\title{
Airflow and microclimate patterns in a one-hectare Canary type greenhouse: an experimental and CFD assisted study
}

\author{
H. Majdoubi ${ }^{1}$; T.Boulard ${ }^{2}$; H. Fatnassi ${ }^{2}$ and L. Bouirden ${ }^{1}$ \\ ${ }^{1}$ Laboratoire de Thermodynamique et Energétique, Faculté des Sciences, Cité Dakhla BP \\ 8106 Agadir, Morocco \\ ${ }^{2}$ UR880 - INRA : Unité de Recherche Intégrés en Horticulture, INRA, 400 route des \\ Chappes PB 167 Sophia Antipolis 06903, France \\ E-mail for corresponding author: boulard@sophia.inra.fr
}

\begin{abstract}
This study presents an analysis of air circulation and microclimate distribution during daytime in a 1-hectare Canary type tomato greenhouse in the coastal area of southern Morocco. The investigation of the climate inside the greenhouse is based on a numerical simulation using a finite volumes method to solve the mass, momentum and energy conservation equations. The main novelty of this simulation lies in the realism of the 3D modelling of this very large agricultural structure with (i) a coupling of convective and radiative exchanges at the surface of the plastic roof cover, (ii) simulation of the dynamic influence of the insect screens and tomato crop on airflow movement, using the concept of porous medium, (iii) simulation, in each grid cell of the crop canopy, of the sensible and latent heat exchanges between the greenhouse air and the tomato crop, and (iv) detailed simulation of climate parameters in a 1-hectare real-scale commercial greenhouse.

The model simulations were first validated with respect to temperature and relative humidity fields measured inside the experimental greenhouse for fairly steady-state outside conditions marked by a prevailing sea breeze around the solar noon. A good agreement was observed between the measured and simulated values for inside air temperatures and specific humidity. It was next used for exploring the details of the inside air temperature and humidity fields and plant microclimates and transpiration fluxes throughout the greenhouse space. Simulation for a wind direction perpendicular to the side and roof openings shows that the insect screen significantly reduced inside air velocity and increased inside temperature and humidity, especially in the vicinity of the crop canopy. It revealed the details of the flow field within the greenhouse. At the windward end of the greenhouse, the flow field was marked by a strong windwise air current above the tomato canopy which was fed by the wind ward side vent, and a slow air stream flowing within the tomato canopy space. Then, from the first third of the greenhouse to the leeward end, the flow field was marked by the combination of wind and buoyancy forces, with warmer and more humid inside air which was evacuated through the upper roof vents, while colder and dryer air was penetrated through the upper roof vent openings. Based on these simulations, design studies of the greenhouse crop system were performed to improve inside air temperature and humidity conditions by simple modifications of orientation of the crop rows.
\end{abstract}

Keywords: Greenhouse; CFD; Modelling, Airflow, Climate distribution, Insect screens, Tomato. 
Version définitive du manuscrit publié dans / Final version of the manuscript published in : Agricultural and Forest Meteorology, 2009, vol.149, no.6-7, DOI : 10.1016/j.agrformet.2009.01.002:

\section{Introduction}

In recent years, a variety of new greenhouse designs have been introduced to meet requirements for agricultural production in Mediterranean regions. The use of Canary type greenhouses (Majdoubi, 2007) has been spreading rapidly in the Canary Island, along the Mediterranean coast of Spain and on the Atlantic coast of Morocco. With a total of about 100,000 hectares (Jouet, 2006), this type of greenhouse is now one of the most widely used in the world. However, because of its design and its use in subtropical regions, this type of structure has a very heterogeneous inside climate, which can be damaging to crop activity, particularly transpiration and photosynthesis. These greenhouses are often very large (1 hectare or more), and sidewall ventilation is more commonly used than roof ventilation; these factors intensify the climatic heterogeneity. Moreover, to reduce the need for pesticide application the vent openings have to be equipped with fine-mesh insect screens. They act as mechanical barriers to insects but also to air and significantly reduce the ventilation rate and thus tend in turn to rise inside air temperature and humidity.

Computational fluid dynamics (CFD) have also been increasingly used to study greenhouse ventilation, whether driven by wind (Mistriotis et al., 1997; Haxaire, 1999) or buoyancy forces, (Lamrani, 1997; Boulard et al., 1999), in both greenhouses and tunnels (Boulard and Wang, 2000).

Recently, Bartzanas et al. (2002) have characterised and numerically modelled the effects of insect screens on ventilation and inside climate in a tunnel greenhouse.

The effects of fine insect screens on the vent openings of Spanish 'Parral' greenhouses or Moroccan 'Canary type' greenhouses have been studied in details and simulated by means of CFD packages. Campen et al. (2003) and Molina-Aiz et al. (2004) have analysed the effect of wind speed on natural ventilation openings in a Spanish 'Parral' type greenhouse equipped with screened top and side ventilation, using a three-dimensional and a two-dimensional CFD simulation respectively. In both studies, the greenhouse-dependent ventilation characteristics and the influence on ventilation rate of wind direction and the geometry of the openings were numerically assessed.

For a commercial Canary type greenhouse of 0.5 ha, equipped with insect screens on side and roof openings, Fatnassi et al.(2003 and 2006) have characterised the inside climate and the air exchange by means of tracer gas measurements, and then used these data to validate a three-dimensional simulation model using a commercial CFD software package (CFD2000).

As they increase in size, and with insect screening now being used systematically on their roof and side openings, Parral and Canary type greenhouses are looking increasingly similar to the large screenhouses used for horticultural production, which are also spreading rapidly in the subtropical and Mediterranean regions. Several studies have recently stressed the similarities between the two types of structure concerning their heat and mass balances (Tanny et al., 2006) and the mechanisms involved in developing their inside climates (Tanny et al., 2003).

Although the Parral or Canary type greenhouse has been intensively studied in last decade, these studies still show some deficiencies which raise questions as to the realism of their climate simulations. The most crucial defect is that they fail to consider the interactions between canopy and air, and to couple convective and radiative exchanges, particularly at the level of the greenhouse roof cover. Similarly, few studies have been based on threedimensional studies for the greenhouses larger than 1 hectare which constitute the majority of the greenhouse area in Morocco.

In a previous study performed in the same greenhouse, Majdoubi et al.(2007) showed that the overall ventilation performance of this type of shelter was hindered both by the insect screening of the vents and the orientation of the tomato rows perpendicularly to the prevailing wind. Therefore, the aim of the present study was to analyse in details the distribution of inside airflow and temperature and humidity fields in interaction with crop rows distribution. 
Version définitive du manuscrit publié dans / Final version of the manuscript published in : Agricultural and Forest Meteorology, 2009, vol.149, no.6-7, DOI : 10.1016/j.agrformet.2009.01.002:

We combined an experimental study and a modelling study of the micro-climate inside a real large scale Moroccan Canary type greenhouse of 1.12 ha equipped with insect screens (called 20/10 for 20 meshes $\mathrm{cm}^{-1}$ along the width and 10 meshes $\mathrm{cm}^{-1}$ along the length), across the roof and sidewall ventilation openings. The greenhouse numerical climate model is based on a commercial CFD (CFD2000®/ Storm) simulation of convective transfers, completed by a simulation, in each grid cell of the canopy, of the sensible and latent heat exchanges between the tomato crop and the greenhouse air (Boulard and Wang, 2000), together with the combination of radiative and convective transfers at roof level (Montero et al., 2005, Ould Khaoua, 2006).

The model was first validated by the measured data and then used to explore the details of air flow, temperature and humidity distribution. This CFD-assisted exploration of the inside climate and air circulation allows for a better assessment of the overall climate and plant activity and more rapid progress towards ways of improving them.

\section{The numerical method}

\subsection{The numerical approach}

The classical mass, momentum, energy and concentration equations can be represented for a steady-state, three-dimensional flow with the following conservation equation:

$$
\frac{\partial \phi}{\partial t} \frac{\partial}{\partial x_{j}}\left(u_{j} \phi\right)=\frac{\partial}{\partial x_{j}}\left(\Gamma_{\phi} \frac{\partial \phi}{\partial x_{j}}\right)+S_{\phi}
$$

where $\phi$ stands for the variables of interest, i.e. the three velocity components $u_{i}\left(\mathrm{~m} . \mathrm{s}^{-1}\right)$, the temperature $T(\mathrm{~K})$, and the specific humidity $w\left(\mathrm{~kg}_{\mathrm{H} 2 \mathrm{O}} \cdot \mathrm{kg}_{\mathrm{moistair}}{ }^{-1}\right) . \Gamma_{\phi}$ and $S_{\phi}$ represent the diffusion coefficient and source term of $\phi$ and a description of their forms can be found in Boulard \& Wang (2000). The system of equations built with these variables is numerically solved with the finite volume method. Algorithms and methods for the resolution of this system of equations can be found in the CFD 2000 (2004) user's guide and will not be repeated here. To model the turbulent constraints using the standard $k-\varepsilon$ turbulence model (Launder and Spalding, 1974), in equation (1) $\phi$ stands also for the turbulent kinetic energy k $\left(\mathrm{m}^{2} \mathrm{~s}^{-2}\right)$ and the dissipation of the turbulent kinetic energy $\varepsilon\left(\mathrm{m}^{2} \mathrm{~s}^{-3}\right)$,

The Boussinesq model was also activated to take account of the gravity effect (Launder \& Spalding, 1974), which means that the buoyancy force due to air density differences is added as a source term of the momentum equation (Boulard et al., 2002).

\subsection{Modeling of flow through insect screens and plants}

For an air speed $u$, the drag forces induced by the insect screens and the crop that correspond to the term $S_{\phi}$ for the equation of motion is included into our CFD study by means of the porous medium approach governed by the Darcy-Forchheimer equation:

$$
S_{\phi}=-\left(\left(\mu / K_{p}\right) u+\left(C_{F} / \sqrt{K_{p}}\right) \rho u^{2}\right)
$$

where $\rho\left(\mathrm{kg} \mathrm{m}^{-3}\right)$ and $\mu\left(\mathrm{kg} \mathrm{s}^{-1} \mathrm{~m}^{-1}\right)$ are respectively air density and dynamic viscosity.

Values of both coefficients, $K_{p}\left(\mathrm{~m}^{2}\right)$ the permeability of the porous medium and $C_{F}$ (-) the nonlinear momentum loss, are deduced from the screen geometric properties (see Appendix 1).

For a crop canopy one considers only the second member (quadratic term) of relation (2). The sink of momentum is then proportional to leaf density and may be expressed by unit volume of the canopy using an other form, the following commonly used formula (Bruse, 1998):

$$
S_{\phi}=-I_{L A v} C_{D} \rho u^{2}
$$

where $I_{L A v}\left(\mathrm{~m}^{2} \cdot \mathrm{m}^{-3}\right)$ is the leaf area index per volume and $C_{D}$ is the drag coefficient of the entire crop canopy. For a mature greenhouse tomato crop, Haxaire (1999) has found $C_{D}=0.32$, using wind tunnel facilities. 
Version définitive du manuscrit publié dans / Final version of the manuscript published in : Agricultural and Forest Meteorology, 2009, vol.149, no.6-7, DOI : 10.1016/j.agrformet.2009.01.002:

1 In summary, for the crop and the range of air speeds observed inside the canopy, the term in $u$ of equation (2) can be omitted in front of the quadratic term and the non-linear momentum loss coefficient $C_{F}$ and the permeability $K_{p}$ of the medium can be deduced from the combination of equations (2) and (3):

$$
C_{F} / \sqrt{K_{p}}=I_{L A v} C_{D}
$$

For our simulations, in a fist step, the tomato crop canopy was assimilated to a single $2.6 \mathrm{~m}$ high stand of porous medium with the same length and width as the greenhouse and with a leaf area index per volume, $I_{L A v}$ equal to $2.3 \mathrm{~m}^{2} \mathrm{~m}^{-3}$ (corresponding to a $I_{L A s}\left(\mathrm{~m}^{2} \mathrm{~m}^{-2}\right)$ of 3 ). In a second step (see Appendix 4), we have parameterized the equivalent porous medium parameters to take into account the case where the leaf area index was arranged, as in the reality, according to rows and inter rows perpendicular to the air direction.

\subsection{Computational meshes and boundary conditions}

The 3D computational domain (Fig. 1) was $43.5 \mathrm{~m}$ high and included the modeled greenhouse (125m long x $90 \mathrm{~m}$ wide x $5.5 \mathrm{~m}$ high), the greenhouse situated leeward and considered as a blockage and their surroundings: the free space windward $(30 \mathrm{~m})$, leeward (90 $\mathrm{m}$ ) and along the sides ( $30 \mathrm{~m}$ to the north and $38 \mathrm{~m}$ to the south) of the greenhouse. After several trials with different grid resolutions, the computational grid was set to the less time consuming: a 192 by 44 by 112 grid using Cartesian Body Fitted Coordinates (BFC) with finer resolutions imposed near the ground, walls and roof, where the thermal gradients were steeper (Fig 1).

The dynamics boundary conditions prescribed a nil vertical pressure gradient in the air at the upper limit of the computational domain, an inlet at the Western lateral limit (see Fig. 1.) and an outlet at the Eastern lateral limit whereas we have only considered conditions of flux conservation at the Southern and Northern sides. The inlet condition at the western side corresponds to the outside air conditions which direction was perpendicular to the West sidewall ventilation openings. A logarithmic profile corresponding to a wind speed profile similar to the one described by Haxaire (1999) for Southern France wind conditions was also specified at the Western boundary.

The thermal boundary conditions at the limits of the studied domain were basically of two types: (i) imposed temperature values equal to those measured during the experiment for the whole air profile at the Western lateral limit and at external soil surface and (ii) an imposed flux at internal soil surface.

Air speed and direction and air and soil surface temperatures and soil surface fluxes together with air humidity were continuously monitored and used as boundary conditions for the numerical simulation (see Table 1).

\subsubsection{Simulation regime}

The simulation was performed for steady state boundary conditions. For meeting this status, we have considered imposed climate and boundary conditions corresponding to measured data performed under clear sky conditions between 10 and $14 \mathrm{~h}$ (solar time) over 3 days $(29 / 09 / 05$ to $01 / 10 / 05)$. In these specific conditions, as sun position is almost fix in the sky and as sea breeze remains almost constant in speed and direction during the measurement period (Demrati et al., 2001), one can thus consider that the boundary conditions remain in quasi permanent regime. Their average and standard deviation values are summarized in Table 1.

\subsubsection{Coupling thermal and water vapour exchanges between crop canopy and air}

The coupled sensible and latent heat balances were considered at the scale of each mesh of the crop cover (approximately $0.3^{3} \mathrm{~m}^{3}$ ) by means of equations describing in permanent 
Version définitive du manuscrit publié dans / Final version of the manuscript published in : Agricultural and Forest Meteorology, 2009, vol.149, no.6-7, DOI : 10.1016/j.agrformet.2009.01.002:

1 regime, the sensible and latent heat exchanges between the air and a virtual "big leaf". 2 Following Boulard \& Wang (2002), the radiative net flux $R_{n e t}\left(\mathrm{Wm}^{-2}\right)$ reaching each mesh of 3 the crop canopy was assimilated to a "volume heat source boundary condition" and 4 partitioned into convective sensible $Q_{\text {sen }}\left(\mathrm{Wm}^{-2}\right)$ and latent heat fluxes $Q_{\text {Lat }}\left(\mathrm{Wm}^{-2}\right)$, depending on the heat and water exchanges between the air and this virtual "big leaf" characterised by its surface temperature $\left(T_{v}\right)$ :

$$
R_{\text {net }}-Q_{\text {sen }}-Q_{\text {lat }}=0
$$

Where the sensible heat flux $Q_{\text {Sen }}$ was expressed with respect to the temperature difference between inside air and canopy (Roy et al, 2008):

$$
Q_{\text {Sen }}=\rho C_{p} I_{L A v}\left(\left(T_{v}-T_{i}\right) / r_{a}\right)
$$

with $T_{v}$ and $T_{i}$ the canopy and inside air temperatures $(\mathrm{K}), C_{p}\left(\mathrm{Jkg}^{-1} \mathrm{~K}^{-1}\right)$ the specific heat of air at constant pressure, $I_{L A v}\left(\mathrm{~m}^{2} \mathrm{~m}^{-3}\right)$ the leaf area index per volume and $r_{a}\left(\mathrm{sm}^{-1}\right)$ the leaf aerodynamic resistance. $Q_{\text {Lat }}$ was deduced from a similar relation with respect to air humidity difference between $w_{v}{ }^{*}$ $\left(\mathrm{kgkg}^{-1}\right)$, the saturated water content of the air at canopy temperature and $w_{i}\left(\mathrm{kgkg}^{-1}\right)$, the specific humidity of the air:

$$
Q_{\text {Lat }}=\rho L_{v} L_{e}^{\frac{1}{3}} I_{L A v}\left(\left(w^{*}{ }_{v}-w_{i}\right) /\left(r_{a}+r_{s}\right)\right)
$$

with the Lewis number $L e=0.86, L_{v}\left(\mathrm{~J} \mathrm{~kg}^{-1}\right)$ the latent heat of water vaporization and $r_{S}\left(\mathrm{sm}^{-1}\right)$ the leaf stomatal resistance.

The details of the equations and the method used to customise the commercial CFD model are described in Appendix 2.

\subsubsection{Coupling convective and radiative exchanges at greenhouse roof level}

Except for very recent studies (Montero et al., 2005; Ould Khaoua, 2006), most authors have considered imposed temperature conditions (measured values) at the greenhouse roof and walls, i.e. inside the studied domain. These imposed boundary conditions inside and not at the boundaries of the simulated domain are in contradiction with the very purpose of the simulation, which is to deduce the state variable inside the studied domain knowing only its boundary conditions. In fact this was due to the failure to couple radiative and convective exchanges, particularly at the roof and walls. In the present study, the contributions of solar and atmospheric radiation have been included in the model by simulating the roof cover energy balance and deducing the resulting roof temperature.

As the plastic cover is very thin $(\approx 200 \mu \mathrm{m})$, one can consider that internal and external roof surfaces have approximately the same temperature and that the energy balance of the roof can be simplified to the following form:

$$
Q_{c}+P_{v} Q_{R_{v, c}}+\left(1-P_{v}\right) Q_{R_{s i, c}}+Q_{R_{s k y, c}}-H_{C c i}-H_{C c e}=0
$$

Where $Q_{c}\left(\mathrm{Wm}^{-2}\right)$ represents the short wavelengths radiative flux absorbed by the roof cover (direct and reflected solar radiation); $Q_{R_{v, c}}\left(\mathrm{Wm}^{-2}\right)$ is the long wavelength exchanged between the canopy and the roof cover, pondered by $P_{v}$, the portion of crop canopy seen by the roof cover; $Q_{R_{s i, c}}\left(\mathrm{Wm}^{-2}\right)$ is the radiative flux in the long wavelength exchanged between the bare ground surface area and the roof cover; $Q_{R_{s y, c}}\left(\mathrm{Wm}^{-2}\right)$ represents the radiative long wavelength flux exchanged between the sky, regarded as a black body, and the roof cover; $H_{C c i}\left(\mathrm{Wm}^{-2}\right)$ represents the convective flux exchanged between the inside surface of the plastic cover and 
Version définitive du manuscrit publié dans / Final version of the manuscript published in : Agricultural and Forest Meteorology, 2009, vol.149, no.6-7, DOI : 10.1016/j.agrformet.2009.01.002:

the inside air and $H_{C c e}\left(\mathrm{Wm}^{-2}\right)$ is the convective flux exchange between the outer surface of the plastic cover and outside air.

Expressing Eq.(8) with respect to the roof temperature $T_{c}$ and the temperatures of the other elements in the greenhouse system, i.e. tomato canopy temperature $T_{v}$, internal soil surface temperature $T_{s i}$, internal and external air temperatures $T_{i}$ and $T_{e}$, and sky temperature $T_{s k y}$, together with their geometrical, optical and thermal properties, one can deduce the plastic cover temperature $T_{c}$ (see Appendix 3). This temperature computation is introduced in the numerical model using the "user defined" options available in the CFD 2000 software (see Appendix 3).

For each trial, about 10 days of uninterrupted calculation time were needed on average before converging to a solution for the greenhouse climate numerical simulation, using a 2.5 $\mathrm{GHz}$ frequency computer with a 512 MBytes random access memory (RAM).

\section{Materials and methods}

\subsection{The greenhouse}

The studied greenhouse (Fig. 2) is a commercial Canary type plastic greenhouse covered with a $200 \mu \mathrm{m}$ thick single-layer polyethylene sheet. The dimensions of this 1.125 -ha area greenhouse are: $90 \mathrm{~m}$ in length, $125 \mathrm{~m}$ in width, $5 \mathrm{~m}$ in height at the gutter and $5.5 \mathrm{~m}$ at the ridges. The spans and the tomato crop rows were oriented North-South, i.e., perpendicular to the direction of the prevailing sea breeze. There is another greenhouse nearby, leeward with respect to the prevailing wind and connected to the first one by an insect screened space (Fig.2).

The greenhouse was provided with natural ventilation by means of seventeen roof vent openings $\left(0.6 \times 125 \mathrm{~m}^{2}\right.$ each, i.e. a total of $\left.1275 \mathrm{~m}^{2}\right)$ covered with insect screens $(20$ meshes $\mathrm{cm}^{-1}$ in width, 10 meshes $\mathrm{cm}^{-1}$ in length, with a wire diameter of $0.28 \mathrm{~mm}$ ). The sidewall ventilation openings were equipped with similar insect screens and the maximum opening areas were $875 \mathrm{~m}^{2}$ on the West-East sides and $630 \mathrm{~m}^{2}$ on the North-South sides. During the experiment, the total roof opening area and total sidewall opening area were maintained throughout at $1275 \mathrm{~m}^{2}$ and $1505 \mathrm{~m}^{2}$ respectively (Fig. 2).

\subsection{Experimental conditions}

The parameters described in Table 2 were systematically recorded, in order (i) to characterise the inside microclimate, (ii) to determine the simulation boundary conditions and (iii) to validate the simulation model. All these measurements were taken every 5 seconds and the data were then averaged and stored every fifteen minutes in two data loggers (Models 21 $\mathrm{X}$ and CR23, Campbell Scientific, Inc., Logan, USA).

The greenhouse was occupied by a tomato crop (Solanum Lycopersicum, cv. Gabriella)

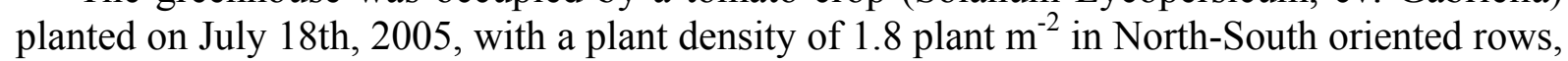
i.e. perpendicular to the direction of the prevailing Westerly sea breeze (Fig. 2), and with a leaf area index $I_{L A S}\left(\mathrm{~m}^{2} \mathrm{~m}^{-2}\right)$ of 3 at the time of the measurements. An explicit description of the spatial variation (rows and between rows of plants) of plant density resolved in the model is presented in Appendix 4. The crop was watered by a drip irrigation system and soil surface was considered as a dry surface.

\section{Results and discussion}

\subsection{Model validation}

\subsubsection{Distributed inside climate}


Version définitive du manuscrit publié dans / Final version of the manuscript published in : Agricultural and Forest Meteorology, 2009, vol.149, no.6-7, DOI : 10.1016/j.agrformet.2009.01.002:

Validation of the numerical model with respect to experimental data measured for the same boundary conditions (Table 1) shows (Fig. 3) that the difference between the simulated and measured air temperature profiles from West to East of the greenhouse ranges between 0.1 and $0.95^{\circ} \mathrm{C}$, with an average difference of $0.61^{\circ} \mathrm{C}$. Examination of the simulated and measured specific air humidity inside the experimental greenhouse at 1 and $4 \mathrm{~m}$ above the soil surface (Fig. 4), demonstrates that the measured and predicted values are very close, the difference ranging between 0 and $0.9 \mathrm{~g} \mathrm{~kg}^{-1}$, with a root mean square error of $0.1 \mathrm{~g} \mathrm{~kg}^{-1}$.

\subsubsection{Greenhouse ventilation rate and crop transpiration flux}

The overall air exchange rate had already been determined and modelled for this particular greenhouse using the overall heat and water vapour balance of the whole greenhouse space (Majdoubi et al., 2007). This approach is similar to the tracer gas method, which minimum accuracy (Ducarme et al., 1994) is estimated to about 30\%. Using this approach, and for the same vent opening area and wind speed conditions as those used as boundary conditions for our simulation (Table 1), one can estimate $\mathrm{G}\left(\mathrm{m}^{3} \mathrm{~s}^{-1}\right)$ the ventilation flow rate in the greenhouse, $G=131.25 \mathrm{~m}^{3} \mathrm{~s}^{-1}$.

Averaging $T_{r}$ the transpiration flux value which was deduced from the numerical model using equation (7) over the whole canopy space

$$
T_{r}=Q_{\text {Lat }} / L_{v}
$$

One finds $\operatorname{Tr}=178.51 \mathrm{~g} \mathrm{~h}^{-1} \mathrm{~m}^{-2}$. This computed value can be compared with an estimation, based on the determination of the overall ventilation rate $G$, of the overall water vapour flux extracted from the greenhouse by ventilation, $Q_{L i, e} / L_{v}$, with :

$$
Q_{L i, e}=\left(\rho G / A_{s i}\right)\left(w_{e}-w_{i}\right)
$$

where $A_{s i}\left(\mathrm{~m}^{2}\right)$ is the greenhouse soil area.

As the tomato plants are watered by drip irrigation, one can consider that soil evaporation is negligible and that the water vapour extracted per $\mathrm{m}^{2}$ from the greenhouse by ventilation $Q_{L i, e} / L_{v}$ must be equal to the canopy transpiration $\operatorname{Tr}$ per $\mathrm{m}^{2}$ of greenhouse soil.

Application for our experimental conditions using the measured climatic data and the estimated overall ventilation rate $G$ gives $Q_{L i, e} / L_{v}=169.61 \mathrm{gh}^{-1} \mathrm{~m}^{-2}$, which is close to the average computed transpiration flux $\operatorname{Tr}=178.51 \mathrm{gh}^{-1} \mathrm{~m}^{-2}$ deduced from the numerical model.

\subsection{Detailed indoor climate and air movement analysis}

The main interest of this numerical simulation lies in the opportunity it provides details on air speed, temperature and humidity distributions throughout the greenhouse domain. We have thus systematically explored the longitudinal and vertical distributions for the main state variables and vectors derived from the model, inside the greenhouse.

\subsubsection{Flow field}

For the same wind direction as the prevailing sea breeze, which blows perpendicularly to the vent openings on the West side, we have plotted a vertical cross-section of the velocity vector field across the middle of the greenhouse (Fig. 5). This shows that air speed in the space between the top of the crop canopy and the greenhouse roof is approximately half that of the outside wind, with the same direction (from West to East). Air velocity is much lower inside the crop canopy than outside (1/10 to $1 / 15$ of outside wind velocity $U_{\text {ext }}$ ) and it flows systematically in a reverse direction, i.e. from the leeward end (East) to the windward end (West) of the greenhouse. A similar observation, but confined to the downstream part of the greenhouse, has already been reported by Fatnassi et al. (2003) for a quite similar greenhouse $\left(5000 \mathrm{~m}^{2}\right)$ equipped with coarser insect screens (6 by 6 meshes) and with roof ventilation 
Version définitive du manuscrit publié dans / Final version of the manuscript published in : Agricultural and Forest Meteorology, 2009, vol.149, no.6-7, DOI : 10.1016/j.agrformet.2009.01.002:

1 openings which were parallel to the prevailing wind direction. Wang (1998) has also
2 evidenced this reverse flow in the whole volume of a $1600 \mathrm{~m}^{2}$ Venlo type greenhouse equipped with discontinuous roof vent openings without insect screens. Based on computational fluid dynamics simulation and validation of the pressure distribution on the roof of a 100 m long commercial multi-span Venlo type glasshouse, Reichrath \& Davies (2001) have also corroborated this phenomenon and shown that it was due to a static pressure difference between the windward and leeward parts of the inside greenhouse air, in relation with the static pressure field due to wind pressure at the outside surface of the greenhouse cover.

Fig. 5 looks more closely at air circulation along one period (it corresponds to one span with alternatively upper and lower vent openings) of the flow pattern inside the greenhouse; it reveals air circulation loops due to buoyancy forces with horizontal axes which develop perpendicularly to the wind direction. In fact, a detailed examination of the cross-section of the vertical flow fields at the level of the roof vents, alternately positioned at the roof ridges and in the dips (not shown here) has also clearly shown that these loops were fed by (cold and dry) outside air coming through the lower roof openings (acting as air inlets) and (warm and humid) inside air exiting through the upper roof openings situated at ridges (acting as air outlets).

The air velocity distribution in a vertical plan situated in the centre of the greenhouse along the West-East axis (Fig.6) allows us to determine the inside air speed more precisely: 0.2 to $0.5 U_{\text {ext }}$ between the top of the canopy and the roof, and 0 to $-0.1 U_{\text {ext }}$ inside the crop canopy. This considerable reduction in air speed, from $0.2-0.5 U_{\text {ext }}$ to $0-0.1 U_{\text {ext }}$ is essentially due to the drag effect of the tomato plant rows, which are exactly perpendicular to the airflow. This observed air speed reduction is consistent with the previous estimation of Majdoubi et al. (2007) for the same greenhouse, of a strong reduction in the overall air exchange rate between inside and outside owing to the drag effect of the canopy.

The air velocity profiles across the middle of the greenhouse at heights of 1,3 and $4 \mathrm{~m}$ (Fig.7) show that inside air velocity at 3 and $4 \mathrm{~m}$ above soil level first strongly decreases in the first $10 \mathrm{~m}$, then increases progressively from the windward end to the leeward end, from approximately $0.25 U_{\text {ext }}$ to $0.73 U_{\text {ext }}$. A similar trend is observed at $1 \mathrm{~m}$ above soil level in the crop canopy, the inside air velocity varying approximately from $-0.07 U_{\text {ext }}$ to $-0.2 U_{\text {ext }}$. One can also see that a periodicity in the air speed profiles at the 1 and $3 \mathrm{~m}$ heights is due to a combination of wind and buoyancy forces imposed by the succession of roof vent openings alternately positioned at the roof ridges and in the dips, thus acting as outlets for the warm and light inside air and as inlets for the cold and heavy outside air. One must stress that similar observations of loops of warm air going out of the greenhouse through the upper vent openings while cold air was entering through the lower vent openings has systematically been reported by most of the authors who have experimentally and numerically studied greenhouse ventilation. Thus, Mistriotis et al.(1997a) and Boulard et al. (1999) have describe these loops for pure free convection in model scales greenhouses, whereas Sase et al. (1984) and Mistriotis et al. (1997b) also describe it for a combination of free and forced convection for both model scale and real size greenhouses.

Overall, one can summarise the complex inside air current as follows: (i) a strong air current fed by the outside wind passes through the greenhouse from the windward to the leeward side openings just above the crop canopy and below the greenhouse roof, and (ii) with a reverse direction and a much lower speed within the crop canopy. In addition, (iii) air loops fed by buoyancy forces due to the inside air temperature differences develop perpendicularly between the top (exit of warm and light air) and bottom (entry of cold and heavy air) roof vent openings and the canopy volume.

\subsubsection{Temperature and humidity patterns}


Version définitive du manuscrit publié dans / Final version of the manuscript published in : Agricultural and Forest Meteorology, 2009, vol.149, no.6-7, DOI : 10.1016/j.agrformet.2009.01.002:

The vertical profile of air temperature in the centre of the greenhouse (Fig.8), shows that high temperatures are confined to the immediate vicinity of all the solid surfaces intercepting the solar radiative flux, but which also slow down the air flow, as it is the case for the roof and soil surfaces and the crop surfaces within the canopy. Overall, the air temperature rise is very sharp, from $303 \mathrm{~K}\left(30^{\circ} \mathrm{C}\right)$ outside the greenhouse and in the inner space between the roof and the top of the canopy to $311 \mathrm{~K}\left(38^{\circ} \mathrm{C}\right)$ at the roof and soil surfaces. Within the crop canopy, air temperature rises from $305 \mathrm{~K}\left(32^{\circ} \mathrm{C}\right)$ at its top to $311 \mathrm{~K}\left(38^{\circ} \mathrm{C}\right)$ near the soil surface.

The longitudinal windwise profile of air temperature across the middle of the greenhouse at heights of 1, 3 and $4 \mathrm{~m}$ (Fig. 3), shows that overall air temperature values are significantly higher near the windward end than at the leeward end. This is in agreement with our analysis of the air circulation pattern showing that air speed and air exchange rate, which evacuate the heat, are higher near the leeward end of the greenhouse than at the windward one. The wide periodic variations in air temperature (approximately 3 to $4 \mathrm{~K}$ ) recorded at a height of $1 \mathrm{~m}$ explain very well the formation of convective loops at this height, induced by buoyancy forces caused by important temperature differences over short vertical and horizontal distances (Fig. 3). Higher above ground level, the temperature field becomes more homogeneous, as is the case at heights of 3 and $4 \mathrm{~m}$ (difference at same height approximately $0.7 \mathrm{~K}$ ) and its absolute value tends to the value of the outside temperature.

The vertical profile of specific air humidity in the centre of the greenhouse (Figure 9) does not exhibit any peaks at these levels as was the case for the temperature profile because plastic roof cover and soil surface do not exchange any water vapour. However, one can state an increase of about $4 \mathrm{~g} \mathrm{~kg}^{-1}$ in specific humidity from the inside greenhouse air just above the canopy to the lower part of the crop canopy.

The longitudinal windwise profiles of specific air humidity at different heights above the ground (Figure 4) don't exhibit, contrary to the air speed and temperature patterns, any strong gradient between the upstream and downstream ends of the greenhouse. The cyclic variations of air humidity, due to the convective loops, are also shown to be much weaker than for air temperature.

In summary, a strong, dry, cold outside air current fed by the wind is confined inside the greenhouse below the roof and just above the crop canopy, inside air speed being greater and air temperature and humidity lower near the upstream end of the greenhouse. As one penetrates down the crop canopy from its top to the soil surface, one can observe a weak reverse flow with respect to the wind direction, with very high air temperature and humidity conditions.

One can reconstitute the main characteristics of air circulation and heat and mass transfers within the greenhouse as follows (Fig 10 a): cold, dry air penetrates through the windward side vent opening. This air is first warmed up, its saturation deficit increasing automatically, allowing an increase in transpiration flux within the canopy and then an increase in specific humidity. This warmer and more humid air is then evacuated by buoyancy forces through the upper roof vent openings (Fig $10 \mathrm{~b}$ ), it is replaced by colder and dryer outside air which penetrates through the lower roof vent openings. Always owing to buoyancy forces between inside warm and humid air and outside cold and dry air, one observes near the leeward end of the greenhouse (Fig $10 \mathrm{c}$ ) a cold and dry reverse flow which penetrates into the greenhouse through the screened space separating the two greenhouses.

\subsection{Canopy transpiration flux}

Under diurnal conditions, canopy transpiration is certainly the most important energy dissipation mechanism in the greenhouse agrosystem, maintaining inside climate conditions in accordance with plant needs. Following Stanhill et al. (1974) one can even say that through 
Version définitive du manuscrit publié dans / Final version of the manuscript published in : Agricultural and Forest Meteorology, 2009, vol.149, no.6-7, DOI : 10.1016/j.agrformet.2009.01.002:

the transpiration mechanism, the crop modify deeply its local climate, a modification which in turn influences strongly transpiration. Our additions to the CFD programme, for coupling aerial transfers and crop transpiration, allowed us to model this mechanism and thus simulate transpiration flux throughout the canopy.

The latent heat flux according to canopy height below a lower roof opening where cold air penetrates is presented in Fig. 11. It shows that the latent heat of the transpiration flux decreases from about $180 \mathrm{Wm}^{-2}$ at the top of the canopy to $135 \mathrm{Wm}^{-2}$ near the soil surface. This $25 \%$ drop, already measured for a greenhouse tomato crop by Boulard et al. (1991), is attributed to two main causes: (i) the reduction in the absorption of overall radiation from the top to the base of the canopy, described in our model by a Beer Lambert law (see equations 2.4 and 2.5 in Appendix 2) and (ii) an increase in the saturation deficit at the base of the canopy, due to temperature increasing more than specific humidity (see Figures 6 and 8); which in turn induces an increase in the stomatal resistance of the canopy leaves (see equation 2.3 in Appendix 2) and reduces transpiration flux.

The longitudinal latent heat flux distribution from West to East at $1 \mathrm{~m}$ above ground (Fig. 12) revealed a considerable spatially cyclic heterogeneity with values ranging between 140 and $155 \mathrm{Wm}^{-2}$. Comparing this cyclic evolution with similar ones evidenced for air speed, temperature and humidity (Figs. 3, 4, 7) allows us to conclude that generally, areas with low transpiration rates also correspond to areas of low air speed, high air temperature and high saturation deficit, both trends significantly increasing stomatal and aerodynamic leaf resistance and reducing crop transpiration rate proportionately.

\subsection{Sensibility study: effect of plant row orientation on inside climate}

In our study, the crop canopy has been treated as a single, large porous-medium block occupying the entire greenhouse soil area, whereas in reality the crops stands occupied only the half of the soil surface. For simulation purposes, the equivalent leaf area index per volume attributed to the plants in the porous-medium block has therefore been divided by two, to compensate for the artificial doubling of the canopy volume.

As the simulation results have underlined the strong influence of the crop canopy on flow and the associated climate fields, we have tried to make the crop row modelling more realistic and to test the effect of plant row orientation on inside climate. The originality of the approach, designed to keep the model simple, is that it preserves a single, large parallelepiped block of canopy occupying the whole greenhouse soil area, with overall porosity properties accounting for the row orientation with respect to the general air circulation.

Three different cases have been considered: (i) the case where the whole leaf area of the canopy is dispersed through the entire volume of the block occupying the whole greenhouse soil area, (ii) the actual case, where the crop canopy rows are perpendicular to the outside wind direction and occupy only the half of the soil surface (leaf surface density per volume of crop row is twice that of case (i)), and finally (iii) a case where the plant rows are parallel to the outside wind (leaf surface density per volume is also twice that of case (i)). Appendix 4 provides, for each case, the equivalent porous-medium properties to be considered for the canopy block.

The results of the simulations presenting the horizontal windwise greenhouse air velocity distribution from West to East at $1 \mathrm{~m}$ height for the three cases of plant distribution considered show (Fig. 13) that with the most realistic case, i.e. case (ii), air speed at $1 \mathrm{~m}$ height within the canopy is even lower than for case (i), and tends to 0. Conversely, orienting the rows in the direction of flow (case (iii)) substantially decreases the drag of the cover and increases air speed at this height. On the contrary, with the crop rows perpendicular to the wind direction (case (ii)), simulations at $1 \mathrm{~m}$ height in the canopy show that the increase of the canopy drag 


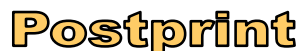

Version définitive du manuscrit publié dans / Final version of the manuscript published in : Agricultural and Forest Meteorology, 2009, vol.149, no.6-7, DOI : 10.1016/j.agrformet.2009.01.002:

1 effect induces with respect to the other two cases respectively a temperature rise of about $1^{\circ} \mathrm{C}$ 2 (Fig. 14) and a humidity rise of about $1 \mathrm{~g} \mathrm{~kg}^{-1}$ (Fig 15).

Conversely, from a practical point of view, it means that temperature and humidity rise at the level of the plant canopy can be reduced by about $25 \%$ by simply orienting the crop rows parallel to the direction of air flow.

\section{Conclusion}

We have seen in this study that an understanding of the air exchange mechanisms between the inside and outside of the greenhouse is crucial for determining the distributed climate of the greenhouse air and canopy. The CFD model of the greenhouse climate, including coupling with the long wave radiative transfers and the effects of plant canopy and insect screens, makes it possible to obtain a true picture of the whole greenhouse volume, including at canopy level. After being verified against the observed data for air, the CFD model can then be used as a powerful tool to explore the climate inside the whole greenhouse volume. One can thus present the continuous distribution of the main state and flux variables of microclimate and crop activity and highlight the factors that shape the inside climate.

In particular, the study shows that even with low outside wind speed as in our case $\left(U_{e x t}=1.3 \mathrm{~m} \mathrm{~s}^{-1}\right)$, the outside wind governs in turn the inside air flow direction, inducing a strong windwise air current above the canopy and a very slow reverse flow inside the crop canopy. The weak air exchange within the canopy governs the climate at this level, with a major increase in air temperature and a more moderate increase in specific humidity. It also shows how buoyancy forces, induced by air temperature and humidity increases, give rise to air loops between the canopy and the roof vents, which in turn tend to accelerate the rate of heat and water vapour evacuation and to improve indoor climate conditions.

As our study of the influence of tomato crop row orientation shows, once the roles of the different mechanisms determining the inside microclimate have been identified in this way, it is possible to test virtual changes to the system so as to quickly identify solutions that will substantially improve its functioning. 
Version définitive du manuscrit publié dans / Final version of the manuscript published in : Agricultural and Forest Meteorology, 2009, vol.149, no.6-7, DOI : 10.1016/j.agrformet.2009.01.002:

\section{References}

2 Bartzanas, T., Boulard, T., Kittas, C., 2002. Numerical simulation of the airflow and temperature distributions in a tunnel greenhouse equipped with insect-proof screen in the openings. Computers and Electronics in Agriculture, 34:207-221.

Boulard, T., Baille, A., Mermier, M., Villette, F., 1991. Mesures et modelisation de la resistance stomatique foliaire et de la transpiration d'un couvert de tomates de serre. Agronomie, vol. 11 No 4, 259-274

Boulard, T., Baille, A., 1995. Modelling of air exchange rate in a greenhouse equipped with continuous roof vents. J. Agricult. Eng. Res. 61, 37-49.

Boulard, T., Haxaire, R., Lamrani, M.A., Roy, J.C., Jaffrin, A., 1999. Characterisation and modelling of the airflow induced by natural ventilation in a greenhouse. J. Agricult. Eng. Res., 74, 135-144.

Boulard, T., Wang, S., 2000. Radiative and convective heterogeneity in a plastic tunnel. 29 th Plasticulture Congress, Hershey, Pennsylvania State University.

Boulard T, Kittas C, Roy JC, Wang S. 2002, Convective and ventilation transfers in greenhouses, Part 2: Determination of the distributed climate. Biosystem Engineering 83 (2), 129-147.

Boulard T., Mermier M., Fargues J., Smits N., Rougier M., Roy JC. 2002. Tomato leaf boundary layer climate: implication for microbiological control of whiteflies in greenhouse. Agricultural Forest Meteorology.110, 159-176.

Boulard T., Wang A., 2002. Experimental and numerical study on the heterogeneity of crop transpiration in a plastic tunnel. Computers \& Electronics in Agriculture, 34, 173-190.

Bruse, M., 1998. Development of a numerical model for the simulation of exchange processes between small scale environmental design and microclimate in urban areas. $\mathrm{PhD}$ Thesis, University of Bochum, Germany.

Campen, J.B., Bot, G.P.A., 2003. Determination of greenhouse-specific aspects of ventilation using three-dimensional computational fluid dynamics. Biosystems Engineering, 84(1), 6977.

CFD2000/Storm v5.0, 2004. CFD systems. Pacific Sierra Corp., USA.

Demrati H., Boulard T., Bekkaoui A., Bouirden L., 2001. Natural ventilation and climatic performance of a large-scale banana greenhouse. J. agri. Engng Res. 80 (3), 261-271.

Ducarme, D., Vandaele L., Wouters P. 1994. Single sided ventilation: a comparison of the measured air change rates with tracer gas and with heat balance approavh. Doc. of BAG meeting on Ventilation Related Aspects in Buildings, pp 26-35.

Fatnassi, H., Boulard, T., Bouirden, L., 2003. Simulation of climatic conditions in full scale greenhouse fitted with insect proof screens. Agric. For. Meteorol.118, 97-111.

Fatnassi, H., Boulard, T., Poncet, C., Chave, M., 2006. Optimisation of greenhouse insect screening with Computational Fluid Dynamics. Biosystems Engineering 93, (3), 301- 312.

Haxaire, R., 1999. Caractérisation et Modélisation des écoulements d'air dans une serre. PhD Thesis, Université de Nice, Sophia Antipolis, France. 148pp

Jouet, J.P., 2006. Global situation of the plasticulture in the world. Comité International des Plastiques en Agriculture, Paris, 40pp.

Lamrani, M.A., 1997. Caractérisation et modélisation de la convection naturelle laminaire et turbulente à l'intérieur d'une serre et de son aération. $\mathrm{PhD}$ Thesis, Université d'Agadir, Morocco.

Launder, B.E., Spalding, D.B., 1974. The numerical computational of Turbulent flows. Comp. Method App. Mech. Eng. 3, 269-289.

Majdoubi, H., 2007. Contribution à la modélisation du microclimat des serres. PhD Thesis, Université Ibn Zohr, Faculté des Sciences d'Agadir, No D55/2007, 215pp. 
Majdoubi, H, Boulard, T., Hanafi, A., Bekkaoui, A., Demrati, H., Fatnassi, H., Nya, M., Bouirden, L., 2007. Natural ventilation performance of a large scale canary greenhouse equipped with insect screens. (Trans of ASABE, in press 50(2)).

Mistriotis, A., Arcidianoco, C, Picuno, P, Bot, G.P.A., Scarascia-Mugnozza, G. (1997a). Computational analysis of ventilation in greenhouses at zero and low-wind-speed. Agricultural and Forest Meteorology, 88, 121-135.

Mistriotis, A., Bot, G.P.A., Picuno, P, Scarascia-Mugnozza, G. (1997b). Analysis of the efficiency of greenhouse ventilation using Computational Fluid Dynamics. JAER, 85, 217-228.

Miguel, A.F, 1998. Air through porous screens: from theory to practical considerations. Energy and Building, 28: 63-69.

Molina-Aiz, F.D., Valera, D.L., Alvarez, A.J., 2004. Measurement and simulation of climate inside Almeria-type greenhouses using computational fluid dynamics. Agricultural and Forest Meteorology, 125: 33-51

Montero, J.I., Munoz, P., Anton, A., Iglesias, N., 2005. Computational Fluid Dynamic modelling of night- time energy fluxes in unheated greenhouses.

Mistriotis, A., Bot, G.P.A., Picuno, P., Searascia-Mugnozza, G., 1997. Analysis of the efficiency of greenhouse ventilation using computational fluid dynamics. Agricult. Forest Meteorol. 85: 217-228.

Ould Khaoua, S., 2006. Modélisation de l'aération naturelle et du microclimat des serres en verre de grande portée sous climat tempéré océanique. Ph D Thesis, Angers (France ) University, 352pp.

Reichrath S., Davies T.W., 2002. Computational fluid dynamics simulation and validation of the pressure distribution on the roof of a commercial multi-span Venlo type glasshouse. Journal of Wind Engineering and Industrial Aerodynamics, 90, 139-149.

Roy J.C, Boulard T, Kittas C, Wang S. 2002. Convective and ventilation transfers in greenhouses, Part 1: The greenhouse considered as a perfectly stirred tank. Biosystem Engineering 83 (1), 1-20. 4

Roy, J.C., Vidal, C., Fargues, J., Boulard, T. (2008). CFD based determination of temperature and humidity at leaf surface. Computers and Electronics in Agriculture ; (61) 201-212.

Sacadura, J.F., 1963. Initiation aux transferts thermiques. CAST, INSA de Lyon Techniques et Documentation, Paris, $445 \mathrm{p}$.

Sase S., Takakura T., Nara M., 1984. Wind tunnel testing on airflow and temperature distribution of a naturally ventilated greenhouse. Acta Horticulturae, 148, 329-336.

Stanhill, G., Scholte-Albers, J., 1974. Solar radiation and water loss from glasshouse roses. J. Am. Soc. Hortic.Sci, 99 (2), 107-110.

Swinbank, W.C., 1963. Long wave radiation from clear skies. Quarterly Journal of the Royal Meteorological Society, 89, 339.

Tanny, J., Cohen, S., Teitel, M., 2003. Screenhouse microclimate and ventilation: an experimental study. Biosystem Engineering, 84 (3), 331-341.

Tanny, J., Haijun, L., Cohen, S., 2006. Airflow charateristics, energy balance and eddy covariance measurements in a banana screenhouse. Agricult. Forest Meteoorol. 139, 105118.

Wang, S., 1998. Measurement and modelling of natural ventilation in a large Venlo type greenhouse. PhD Thesis, Faculté Universitaire des Sciences Agronomiques de Gembloux, Belgique, 194pp. 


\section{Appendix 1: Determination of the aerodynamic proprieties $\left(K_{p}\right.$ and $\left.C_{F}\right)$ of the screen.}

The values of the aerodynamic proprieties $\left(K_{p}\right.$ and $\left.C_{F}\right)$ of the screen have been deduced from the literature using Miguel et al (1998) approach based on their correlations with the porosity of the net:

$$
\begin{gathered}
K_{p}=3.4410^{-9} \alpha^{1.6} \\
C_{F}=4.3010^{-2} / \alpha^{2.13}
\end{gathered}
$$

where $\alpha$ is the screen porosity (-) deduced from the dimensions of the thread (Miguel, 1998):

$$
\alpha=L x W /((L+d)(W+d))
$$

with $L=0.788 \mathrm{~mm}$ and $W=0.255 \mathrm{~mm}$ are respectively meshes length and width, and $d=0.28 \mathrm{~mm}$, is the wire diameter.

The computed values used in equations (1.1), (1.2) and (1.3) for determining the aerodynamic proprieties $\left(K_{p}\right.$ and $\left.C_{F}\right)$ of the (20x10) screen used in the studied greenhouse are $\alpha=0.35, \mathrm{~K}=6.410^{-10}, \mathrm{C}_{\mathrm{F}}=0.402$.

\section{Appendix 2: Sensible and latent heat coupling between air and canopy}

The sensible and latent heat transfer coupling between air and canopy was considered by "customizing" the CFD code by means of an appropriate "Source model" (Haxaire, 1999) available with the CFD software :

$$
\text { Source }=\text { Coef } \times(\text { value }- \text { Dependent variable })
$$

where the terms in this equation were identified to the terms of the sensible and latent heat transfer equations between plant and air within each mesh of the canopy, i.e. for the temperature :

Coef $=I_{L A v} \rho C p / r_{a}$ and value $=T_{v}$,

and for air humidity:

Coef $=I_{L A v} \rho L_{v} L_{e}^{\frac{1}{3}} /\left(r_{a}+r_{s}\right)$ and value $=w_{v} *$.

The value of the aerodynamic resistance $r_{a}$ was deduced from the air speed within each mesh of the canopy using a relation pertaining for greenhouse crop conditions (Boulard et al., 2002):

$$
r_{a}=\rho C_{p} / 0.288 \lambda\left(d_{v} v /\|\vec{U}\|\right)^{0.5}
$$

where $d_{v}(\mathrm{~m})$ is the mean characteristic length of the leaf; and $U\left(\mathrm{~m} \mathrm{~s}^{-1}\right)$ is the interior air speed within each mesh of the crop canopy domain; $\lambda\left(\mathrm{W} \mathrm{m}^{-1} \mathrm{~K}^{-1}\right)$ is air thermal conductivity and $v\left(\mathrm{~m}^{2} \mathrm{~s}^{-1}\right)$ is air viscosity.

Tomato leaf stomatal resistance was deduced from air temperature and saturation deficit values using Boulard et al (1991) formulation:

$$
r_{s}=r_{s_{\min }}\left\{1+0.11 \exp \left[0.34\left(6.10710^{\frac{7.5 T_{i}}{237.5+T_{i}}}-1629 w_{i}-D_{\max }\right)\right]\right\}
$$

where: $r_{s_{\min }}=150 \mathrm{~s} \mathrm{~m}^{-1}$ and $D_{\max }=10 \mathrm{hPa}$.

Because of light interception within the canopy, we have expressed the solar radiation received at an height $z(\mathrm{~m})$ by means of a Beer's law according to the following equation:

$$
\begin{gathered}
R(z)=R_{g i} \exp \left(-k_{c} I_{L A s}(H-z) / H\right) \\
R_{a b s}=R\left(z_{1}\right)-R\left(z_{2}\right)=d R(z)
\end{gathered}
$$

Where $R_{g i}\left(\mathrm{~W} . \mathrm{m}^{-2}\right)$ is the global radiation inside the greenhouse and over the canopy; $k_{c}$ is the extinction coefficient of radiation, set to 0.75 for a tomato crop, $H(\mathrm{~m})$ is the total height of the canopy, $I_{L A S}$ is the crop stand leaf area index $\left(\mathrm{m}^{2} \mathrm{~m}^{-2}\right)$ and $\mathrm{z}_{1}$ and $\mathrm{z}_{2}$ are two arbitrary heights . 


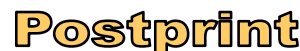

Version définitive du manuscrit publié dans / Final version of the manuscript published in : Agricultural and Forest Meteorology, 2009, vol.149, no.6-7, DOI : 10.1016/j.agrformet.2009.01.002:

Finally, neglecting the long waves radiations in front of solar ones, tomato crop temperature $\left(T_{v}\right)$ can be calculated according to the following equations:

$$
T_{v}=T_{i}+\frac{r_{a} C}{\rho C_{p}}=T_{i}+\frac{r_{a}}{\rho C_{p}}\left[\frac{1}{2 I_{L A v}}\left(\frac{d R(z)}{d z}-\rho L_{v} \frac{w i-w_{a}}{r_{t}} I_{L A v}\right)\right]
$$

\section{Appendix 3: Coupling the convective and radiative transfers at roof level.}

$Q_{c}\left(\mathrm{~W} \cdot \mathrm{m}^{-2}\right)$ used in Eq. (8), corresponds to the radiative balance of the plastic cover in the domain of the short wave lengths. It can be expressed according to:

$$
Q_{c}=\alpha_{S c} R_{g e}+\alpha_{S c} \rho_{S v} \tau_{S c} P_{v} R_{g e}+\alpha_{S c} \rho_{S s} \tau_{S c}\left(1-P_{v}\right) R_{g e}
$$

with $\alpha_{S c}$ and $\tau_{S c}$ the short wavelength absorption and transmission coefficients of the plastic cover respectively; $R_{g e}\left(\mathrm{~W} \mathrm{~m}^{-2}\right)$ is the outside radiation; $\rho_{S v}$ is the short waves reflection coefficient of the canopy and $\rho_{S s}$ is the short waves reflection coefficient of the soil surface. Note that the optical insect proof nets properties are not considered in this equation because they represent less than $10 \%$ of the roof area and also because their properties are very similar to these of the plastic film.

The long wavelength radiative flux exchanged between the canopy and the roof cover $Q_{R v, c}\left(\mathrm{~W} . \mathrm{m}^{-2}\right.$ ) used in Eq. (8) can be expressed as (Majdoubi, 2007):

$$
Q_{R_{v, c}}=\frac{\sigma\left(T_{v}^{4}-T_{c}^{4}\right)}{\frac{1}{\varepsilon_{v}}+\frac{A_{v}}{A_{c}}\left(\frac{1}{\varepsilon_{c}}-1\right)}
$$

with $\varepsilon_{v}$ the crop emissivity; $A_{v} / A_{c}$ being the view factor from the crop cover to the roof with $A_{v}\left(\mathrm{~m}^{2}\right)$ and $A_{c}\left(\mathrm{~m}^{2}\right)$ the vegetation and the roof cover surface area respectively.

Likewise, $Q_{R_{s i c}}\left(\mathrm{~W} . \mathrm{m}^{-2}\right)$ used in Eq. (8) is the long wavelength radiative flux exchanged between the soil surface and the roof cover can be expressed as :

$$
Q_{R_{s i, c}}=\frac{\sigma\left(T_{s i}^{4}-T_{c}^{4}\right)}{\frac{1}{\varepsilon_{s i}}+\frac{A_{s i}}{A_{c}}\left(\frac{1}{\varepsilon_{c}}-1\right)}
$$

with $\varepsilon_{s i}$ the soil surface emissivity and $A_{s i} / A_{c}$ the view factor from the soil surface to the roof, with $A_{s i}\left(\mathrm{~m}^{2}\right)$ the soil surface area.

$Q_{R_{\text {ture }}}$ (W.m ${ }^{-2}$ ) used in Eq. (8) is the long wavelength radiative flux exchanged between the sky, considered as a black body, and the roof cover :

$$
Q_{R_{s k y, c}}=\varepsilon_{c} \sigma\left(T_{s k y}^{4}-T_{c}^{4}\right)
$$

with $\varepsilon_{c}$ the plastic cover emissivity; $\sigma=5.6710^{-8}\left(\mathrm{~W} \mathrm{~m}^{-2} \mathrm{~K}^{-4}\right)$ the Stefan-Boltzmann constant. Sky temperature, $T_{s k y}(\mathrm{~K})$, can be approximated from the external air temperature according to Swinbank (1963) formula relating sky temperature $T_{S k y}$ to outside air temperature $T_{e}$ and a cloudiness factor $F_{c n}\left(0<F_{c n}<1\right)$ :

$$
T_{\text {Sky }}=F_{c n} T_{e}+\left(1-F_{c n}\right) T_{e}^{1.5}
$$

Following Sacadura (1963), for "small" temperature differences between the elements of the radiative exchange system $(\Delta T \leq 100 \mathrm{~K})$, one can linearize the relations (3.2), (3.3) and (3.4) as follows: 


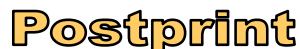

Version définitive du manuscrit publié dans / Final version of the manuscript published in : Agricultural and Forest Meteorology, 2009, vol.149, no.6-7, DOI : 10.1016/j.agrformet.2009.01.002:

$$
Q_{R_{v, c}}=\frac{h_{r l}\left(T_{v}-T_{c}\right)}{\frac{1}{\varepsilon_{v}}+\frac{A_{v}}{A_{c}}\left(\frac{1}{\varepsilon_{c}}-1\right)}
$$

with: $h_{r 1}=4 \sigma \varepsilon_{v} T_{v}^{3}$

$$
Q_{R_{s, c}}=\frac{h_{r 2}\left(T_{s i}-T_{c}\right)}{\frac{1}{\varepsilon_{s i}}+\frac{A_{s i}}{A_{c}}\left(\frac{1}{\varepsilon_{c}}-1\right)}
$$

$4 \quad$ with : $h_{r 2}=4 \sigma \varepsilon_{s i} T_{s i}^{3}$

$$
Q_{R_{s y, c}}=h_{r 3} \varepsilon_{c}\left(T_{s k y}-T_{c}\right)
$$

with, $h_{r 3}=4 \sigma T_{s k y}^{3}$

$H_{C c i}$ the sensible flux which is exchanged at the level of the internal face of the plastic roof cover can be given by:

$$
H_{C c i}=K_{c i}\left(T_{c}-T_{i}\right)
$$

$H_{C c e}$ represents the convective exchange at the level of the external face of the plastic roof cover and can be expressed as follow :

$$
H_{C c e}=K_{c e}\left(T_{c}-T_{e}\right)
$$

where $K_{c i}$ and $K_{c e}$ are respectively the convective exchange coefficients of the two faces 14 of the plastic roof cover $\left(\mathrm{Wm}^{-2} \cdot \mathrm{K}^{-1}\right)$. If we take in first approximation $K_{c i}=K_{c e}=5.38 \frac{U_{e x t} \frac{4}{5}}{d^{1 / 5}}$ for a turbulent forced convection regime (Roy et al., 2002), the plastic cover temperature $\left(T_{c}\right)$ 16 can then finally be expressed as:

$T_{c}=\frac{\alpha_{S c} R_{g e}+\alpha_{S c} \rho_{S v} \tau_{S c} P_{v} R_{g e}+\alpha_{S c} \rho_{S s} \tau_{S c}\left(1-P_{v}\right) R_{g e}+h_{r 3} T_{s k y}+A h_{r 1} T_{v}+B h_{r 2} T_{s i}+K_{c e}\left(T_{i}+T_{e}\right)}{h_{r 3}+A h_{r 1}+B h_{r 2}}$

18 With:

$$
A=\frac{P_{v}}{\frac{1}{\varepsilon_{v}}+\frac{A_{v}}{A_{c}}\left(\frac{1}{\varepsilon_{c}}-1\right)} \text { and } B=\frac{\left(1-P_{v}\right)}{\frac{1}{\varepsilon_{s i}}+\frac{A_{s i}}{A_{c}}\left(\frac{1}{\varepsilon_{c}}-1\right)}
$$


Version définitive du manuscrit publié dans / Final version of the manuscript published in : Agricultural and Forest Meteorology, 2009, vol.149, no.6-7, DOI : 10.1016/j.agrformet.2009.01.002:

\section{1}

\section{Appendix 4: Equivalent porous medium parameters value corresponding to different plant distributions with respect to the prevailing airflow.}

For the calculation of the equivalent porous medium parameters value corresponding to the three different plants distributions with respect to the prevailing airflow, we have considered the combinations of resistances to air flow given in Fig. 16. $R_{v}$ is the resistance of the plant row to air flow, $R_{0.5 v}$ is the same resistance for the case where the plant canopy is dispersed on the whole greenhouse soil area, and $R_{\text {air }}$ is the resistance of the inter rows to air flow.

Following Bernoulli's approach, one can express the pressure drop $\triangle P$ of a porous medium as a function of a discharge coefficient $\mathrm{Al}$ as follows:

$$
\Delta P=0.5 \frac{\rho}{A l^{2}} U^{2}
$$

If $A l_{v}$ is the discharge coefficient of air through the plant canopy arranged in rows, with respect to Eq. (4.1.) the corresponding pressure drop is $\Delta P_{v}$ with $1 / A l_{v}{ }^{2}=R_{v}$.

Likewise if $A l_{a}$ the discharge coefficient of air crossing the inter rows, the corresponding pressure drop is $\Delta P_{\text {air }}$ and $l / A l_{a}{ }^{2}=R_{\text {air }}$.

In the case (i) where the leaf area is dispersed into the whole canopy block, air must only overcome the pressure drop of the canopy considered with a half actual $I_{L a v}$ value and the total pressure drop is given by :

$$
\Delta P_{t o t}=0.5 \frac{\rho}{A l_{0.5 v}^{2}} U^{2}
$$

In the case (ii) where the leaf area index is arranged according to rows perpendicular to the air direction, air must overcome the resistances of a stand of vegetation and of an inter row considered in serials, the total pressure drop can then be given by:

$$
\Delta P_{t o t}=0.5 \rho\left[\frac{1}{A l_{a}^{2}}+\frac{1}{A l_{v}^{2}}\right] U^{2}=0.5 \frac{\rho}{A l_{e}^{2}} U^{2}
$$

where $A l_{e}$ is the equivalent discharge coefficient of air for the row and inter row arrangement. In the case (iii) where the leaf area index is arranged according to rows parallel to the air direction, air must overcome the resistances of stands of vegetation and of an inter rows considered in parallel and the total pressure drop can be given by:

$$
\Delta P_{t o t}=0.5 \rho\left[\frac{\frac{1}{A l_{a}^{2} \cdot A l_{v}^{2}}}{\frac{1}{A l_{a}^{2}}+\frac{1}{A l_{v}^{2}}}\right] U^{2}=0.5 \frac{\rho}{A l_{e}^{2}} U^{2}
$$
opening (i.e. $A l_{l}=0.7$, Boulard and Baille (1995)) and substituting this value and those of $A l_{v}$ and $A l_{0.5 \mathrm{v}}$ in relations (4.2 to 4.4) one finds $A l_{e}$ values corresponding to the porous medium properties for respectively the cases (i) to (iii).

$\begin{array}{cccc} & \text { Case (i) } & \text { Case (ii) } & \text { Case (iii) } \\ \text { Ale } & 0.96 & 0.52 & 1.05\end{array}$




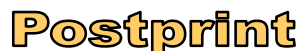

Version définitive du manuscrit publié dans / Final version of the manuscript published in : Agricultural and Forest Meteorology, 2009, vol.149, no.6-7, DOI : 10.1016/j.agrformet.2009.01.002:

TABLES

Table 1: Experimental measurement (mean and standard deviation) performed outside the greenhouse between 10 and $14 \mathrm{~h}$ (solar time) every 15 minutes during 3 days (29, 30

4 September and 01 October 2005) and used as boundary conditions for the numerical 5 simulation.

\begin{tabular}{lcc}
\hline \multicolumn{1}{c}{ Parameters } & Mean & S.D \\
\hline Outside temperature $T_{e}\left({ }^{\circ} \mathrm{C}\right)$ & 29.74 & 0.95 \\
Outside relative humidity $R H_{e}(\%)$ & 45.08 & 2.6 \\
Sky temperature $T_{\text {sky }}\left({ }^{\circ} \mathrm{C}\right)$ & 17.83 & 1.15 \\
Outside soil surface temperature $T_{s i}\left({ }^{\circ} \mathrm{C}\right)$ & 36,67 & 0.88 \\
Wind direction $D_{\mathrm{v}}\left(\mathrm{degree}^{-1}\right)$ & 105.73 & 7.45 \\
Wind speed $U_{\text {ext }}\left(\mathrm{m} \mathrm{s}^{-1}\right)$ & 1.3 & 0.27 \\
Net radiation $R_{\text {net }}\left(\mathrm{W} \mathrm{m}^{-2}\right)$ & 298.75 & 24.3 \\
Inside soil heat flux $F_{S}\left(\mathrm{~W} \mathrm{~m}^{-2}\right)$ & 50 & 1.11 \\
\hline
\end{tabular}

Table 2: Measured parameters, sensors used and locations

\begin{tabular}{|l|l|l|}
\hline \multicolumn{1}{|c|}{ Mesured parameters } & \multicolumn{1}{c|}{ Sensors name } & \multicolumn{1}{c|}{ Locations } \\
\hline Inside net radiation $R_{\text {net }}\left(\mathrm{W} \mathrm{m}^{-2}\right)$ & Net radiometer Q-7 & $\begin{array}{l}\text { between the top of the crop } \\
\text { and the roof cover }\end{array}$ \\
\hline $\begin{array}{l}\text { Soil heat flux exchange at } \\
\text { ground surface } F_{S}\left(\mathrm{~W} \mathrm{~m}^{-2}\right)\end{array}$ & Soil heat flux HFT3 & $1 \mathrm{~mm}$ below the soil surface. \\
\hline $\begin{array}{l}\text { Inside air temperature } T_{i}(\mathrm{~K}) \\
\text { and relative humidity } R H_{i}(\%)\end{array}$ & $\begin{array}{l}\text { Thermo-hygrometer } \\
\text { probes HMP45 AC } \\
\text { protected by radiation } \\
\text { shields. }\end{array}$ & $\begin{array}{l}1 \mathrm{~m} \text { and } 4 \text { m above soil level } \\
\text { at } 10 \text { locations along an East- } \\
\text { West line across the } \\
\text { greenhouse, halfway of its } \\
\text { North-South length }\end{array}$ \\
\hline $\begin{array}{l}\text { The temperatures of the inside } \\
\text { soil surface }\left(T_{s i}\right), \text { roof cover }\left(T_{c}\right) \\
\text { and tomato leaves }\left(T_{v}\right)\end{array}$ & $\begin{array}{l}\text { Thermocouples } \\
\text { (Copper- Constantan })\end{array}$ & $\begin{array}{l}\text { were stuck respectively to } \\
\text { the plastic cover and } \\
\text { positioned 1mm below the } \\
\text { soil surface, a fine } \\
\text { thermocouples which were } \\
\text { inserted in the principal vein } \\
\text { of the terminal leaflet, on its } \\
\text { underside }\end{array}$ \\
\hline $\begin{array}{l}\text { The outside wind speed } U_{e x t} \text { and } \\
\text { direction } D_{w}\end{array}$ & $\begin{array}{l}\text { Cup anemometer A } \\
100 \mathrm{R} \text { and Wind vane } \\
\text { W200P }\end{array}$ & $\begin{array}{l}3 \text { m above the greenhouse } \\
\text { ridge }\end{array}$ \\
\hline $\begin{array}{l}\text { The outside air temperature } T_{e} \\
(\mathrm{~K}) \text { and relative humidity } R H_{e} \\
(\%)\end{array}$ & $\begin{array}{l}\text { Thermo-hygrometer } \\
\text { probe HMP45 AC }\end{array}$ & $\begin{array}{l}3 \mathrm{~m} \text { above the greenhouse } \\
\text { ridge }\end{array}$ \\
\hline Outside radiation $R g_{e}$ & $\begin{array}{l}\text { Pyranometer SP-LITE, } \\
\text { Kipp \& Zonen }\end{array}$ & $\begin{array}{l}3 \text { m above the greenhouse } \\
\text { ridge }\end{array}$ \\
\hline
\end{tabular}

\section{FIGURES}




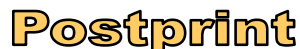

Version définitive du manuscrit publié dans / Final version of the manuscript published in : Agricultural and Forest Meteorology, 2009, vol.149, no.6-7, DOI : 10.1016/j.agrformet.2009.01.002:

1

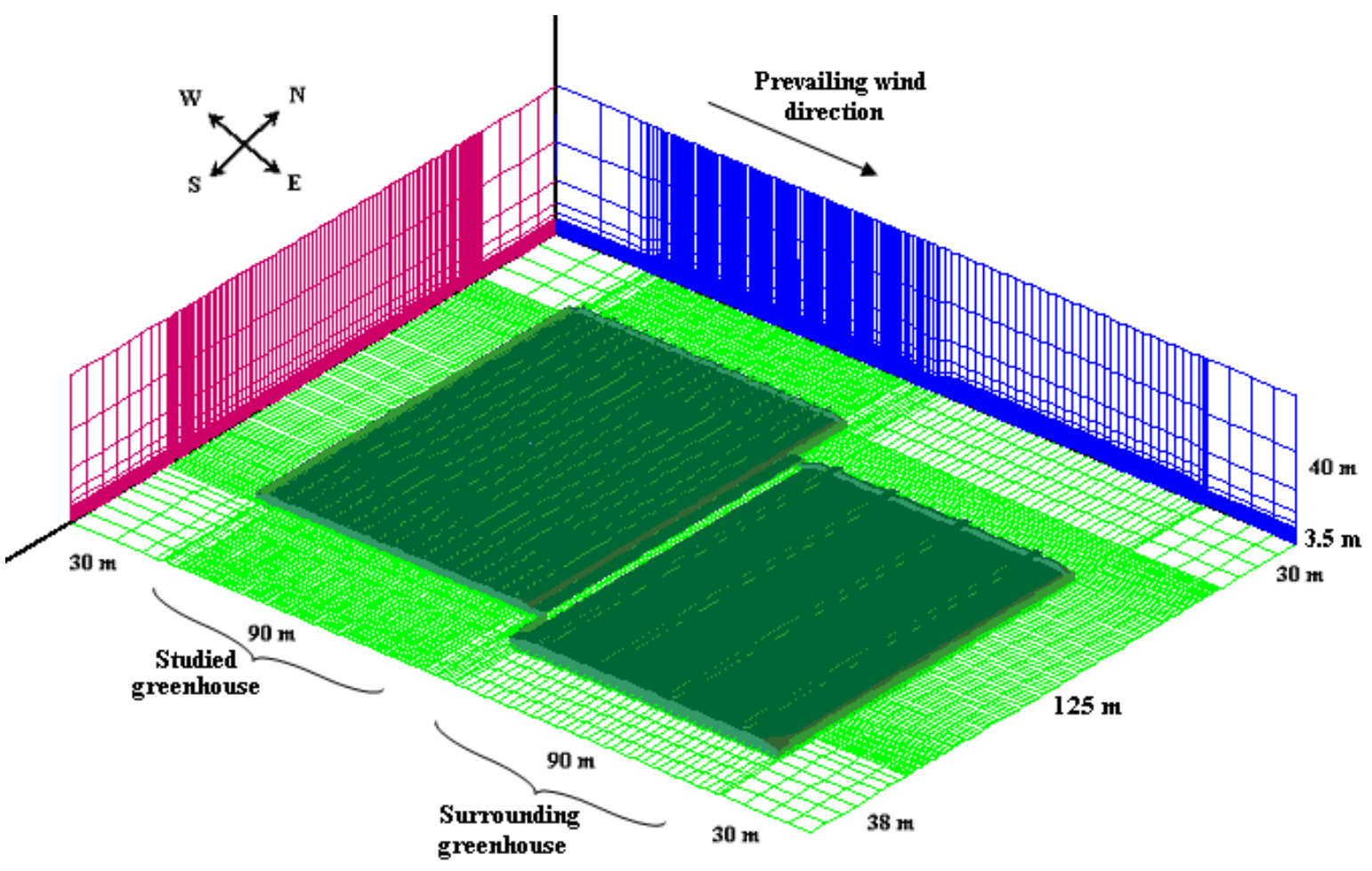

Fig. 1. View of the computational grid of the whole studies $3 D$ domain for the CFD simulation. Gridcell dimensions inside the greenhouse vary between $(0.26,0.44,0.032)$ near the soil and walls and $(0.75,1.25,0.1)$ at $2.5 \mathrm{~m}$ high. 


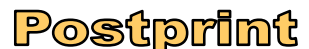

Version définitive du manuscrit publié dans / Final version of the manuscript published in : Agricultural and Forest Meteorology, 2009, vol.149, no.6-7, DOI : 10.1016/j.agrformet.2009.01.002

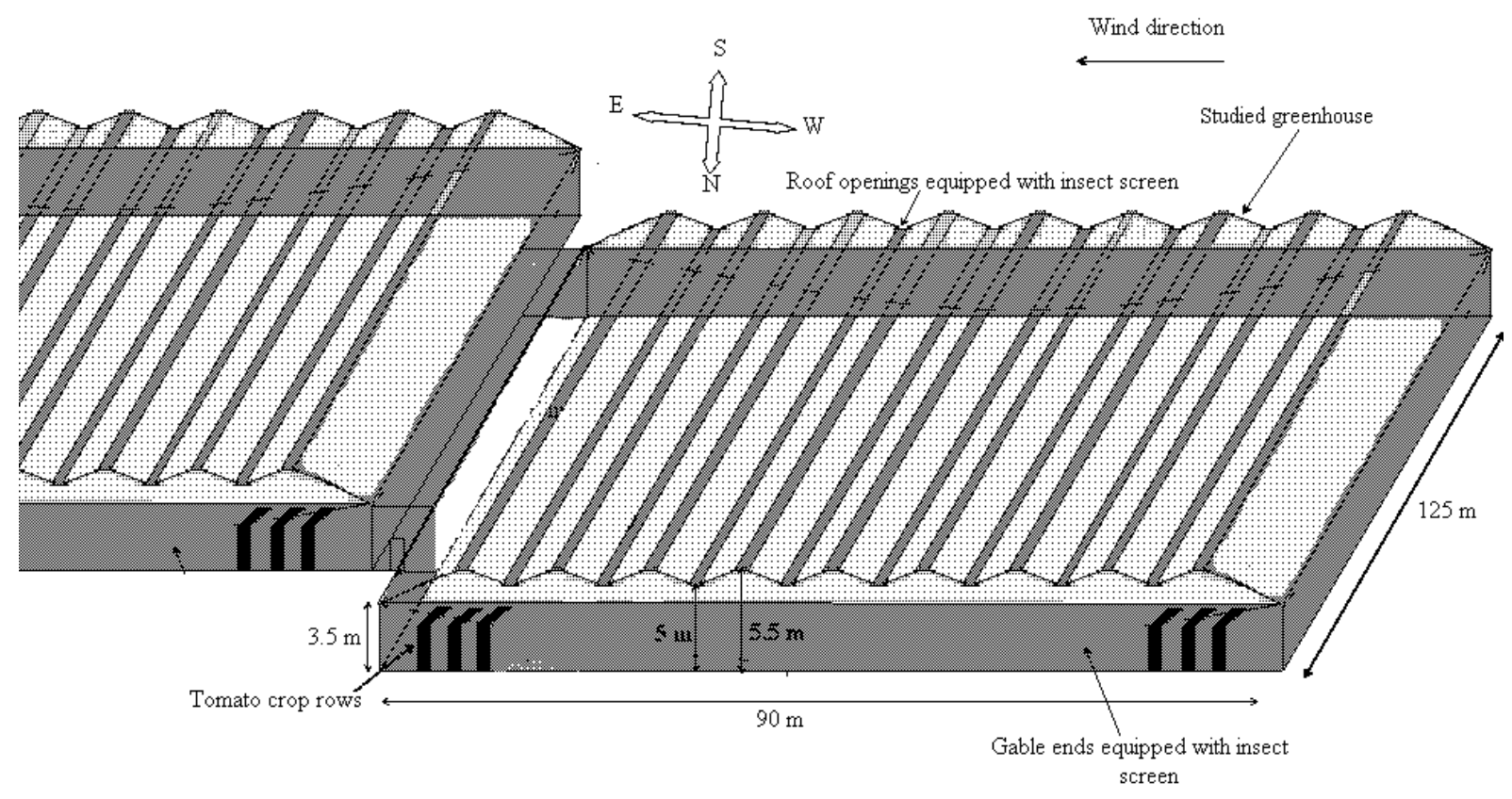

Insect proof nets on the vent openings

$200 \mu \mathrm{m}$ thick continuous plastic sheet

Fig.2. Schematic view of the studied greenhouse, its ventilation system and the surrounding (note that in this scheme, the West direction is on the right) 


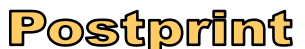

Version définitive du manuscrit publié dans / Final version of the manuscript published in : Agricultural and Forest Meteorology, 2009, vol.149, no.6-7, DOI : 10.1016/j.agrformet.2009.01.002:

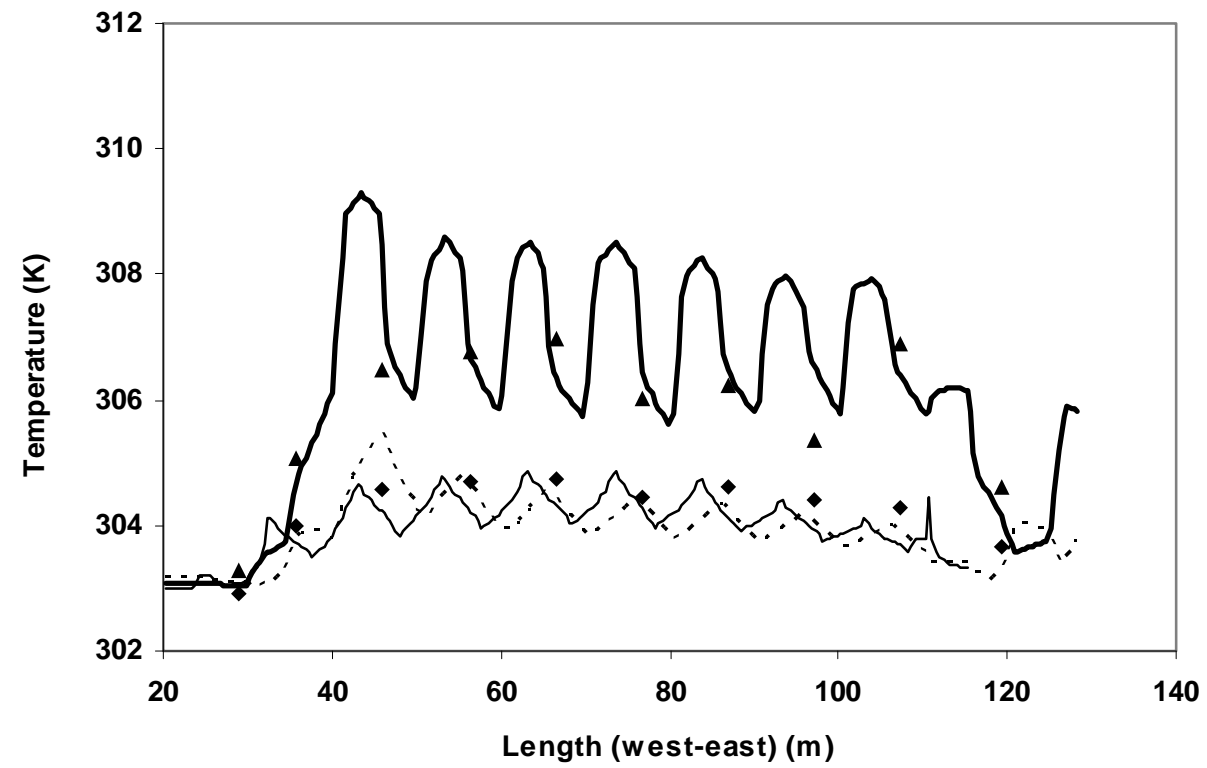

Fig.3. Simulated and measured air temperature profiles from West to East of the greenhouse, halfway along its North-South length:

Measured values $1 m(\mathbf{\Delta}) 4 m(\bullet)$ above soil level

Simulated values $1 \mathrm{~m}$ (—); 3 m (_-....); 4 m (—) 
Version définitive du manuscrit publié dans / Final version of the manuscript published in : Agricultural and Forest Meteorology, 2009, vol.149, no.6-7, DOI : 10.1016/j.agrformet.2009.01.002:

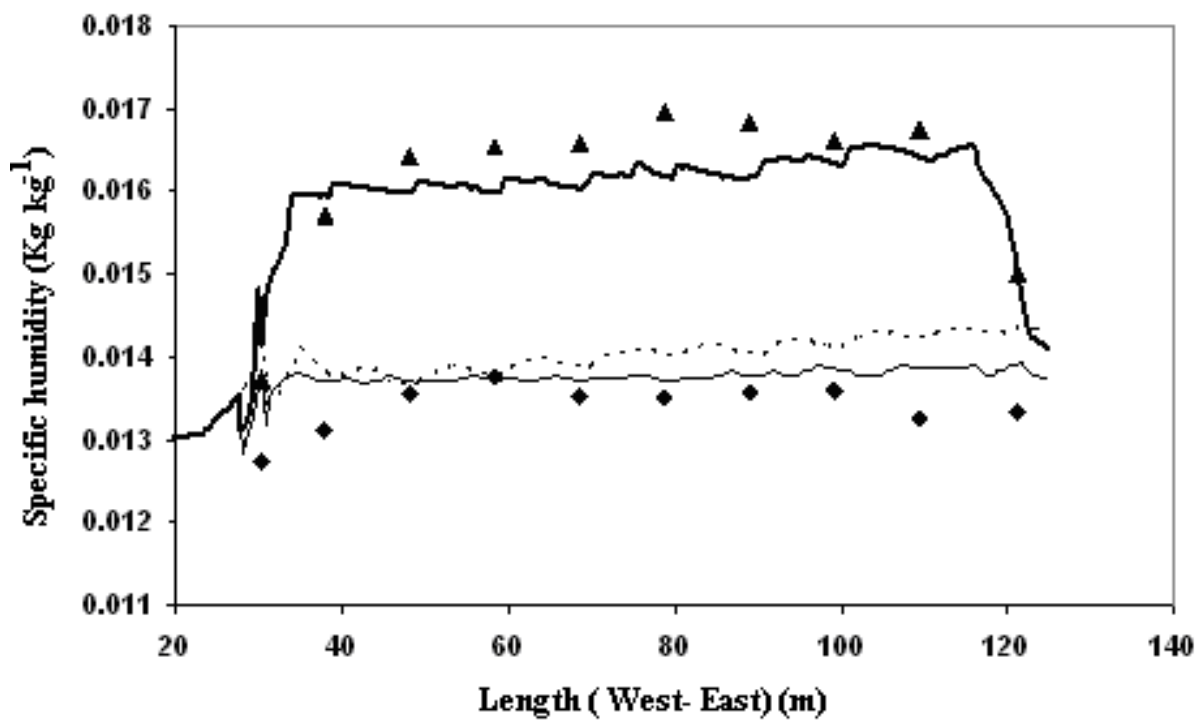

Fig.4. Simulated and measured air humidity profiles from West to East of the greenhouse, halfway along its North-South length:

Measured values $1 m(\mathbf{\Delta}) 4 m(\bullet)$ above soil level

5

6

7 


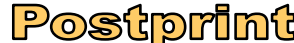

Version définitive du manuscrit publié dans / Final version of the manuscript published in : Agricultural and Forest Meteorology, 2009, vol.149, no.6-7, DOI : 10.1016/j.agrformet.2009.01.002:

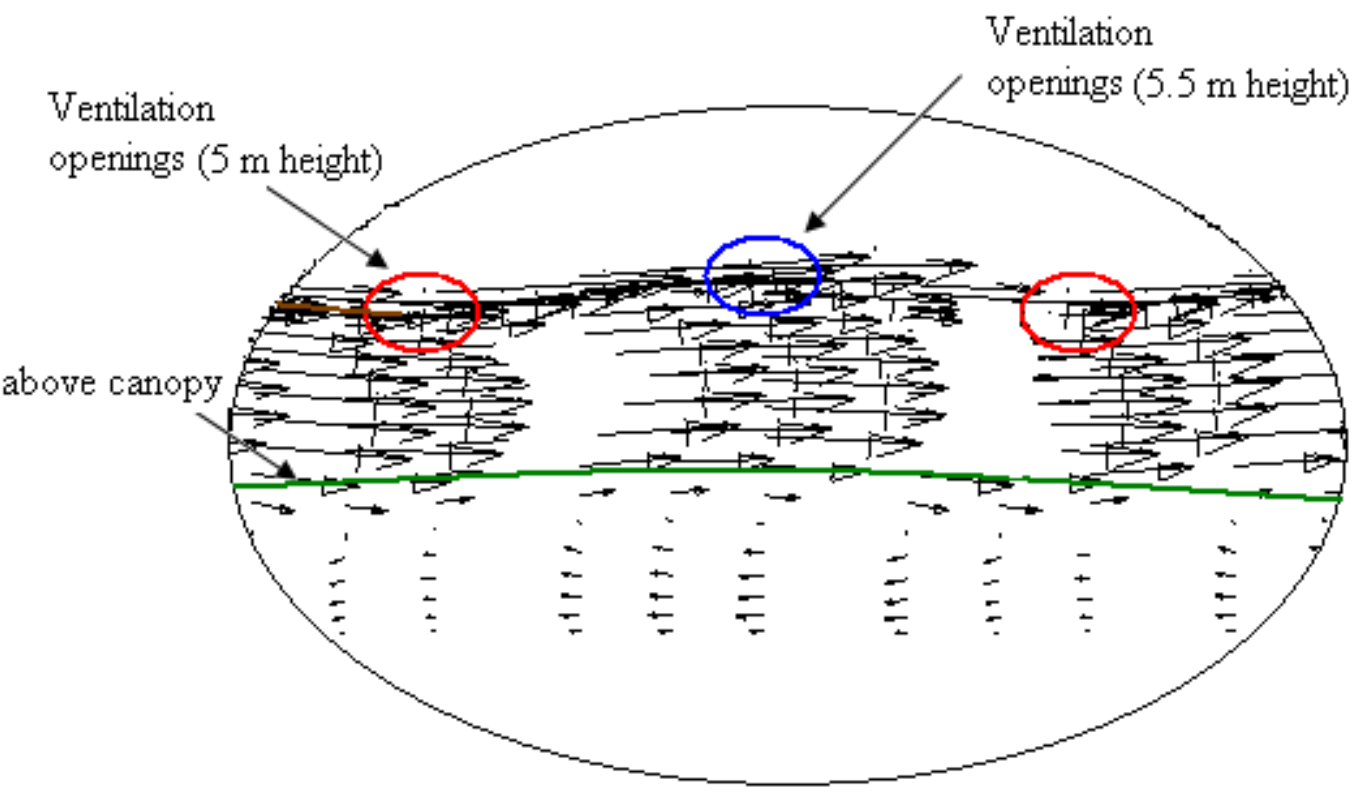
Fig.5. Simulated vertical cross-section of the wind vector field across the middle of the
greenhouse along $W$-E direction
grig. Simulated vertical cross-section the midale of the
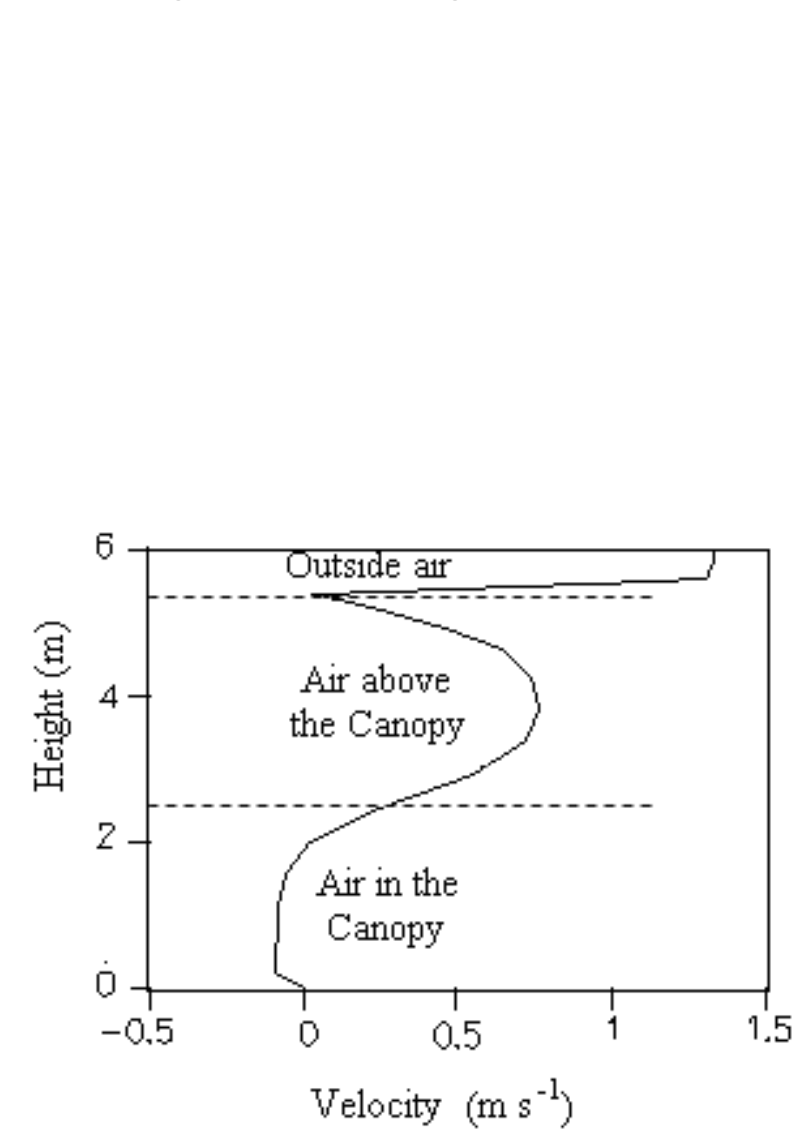

Fig.6. Modelled profile of mean horizontal wind speed in the centre of the greenhouse. 


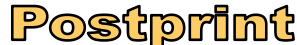

Version définitive du manuscrit publié dans / Final version of the manuscript published in : Agricultural and Forest Meteorology, 2009, vol.149, no.6-7, DOI : 10.1016/j.agrformet.2009.01.002:

2

3

4

5

6

7

8

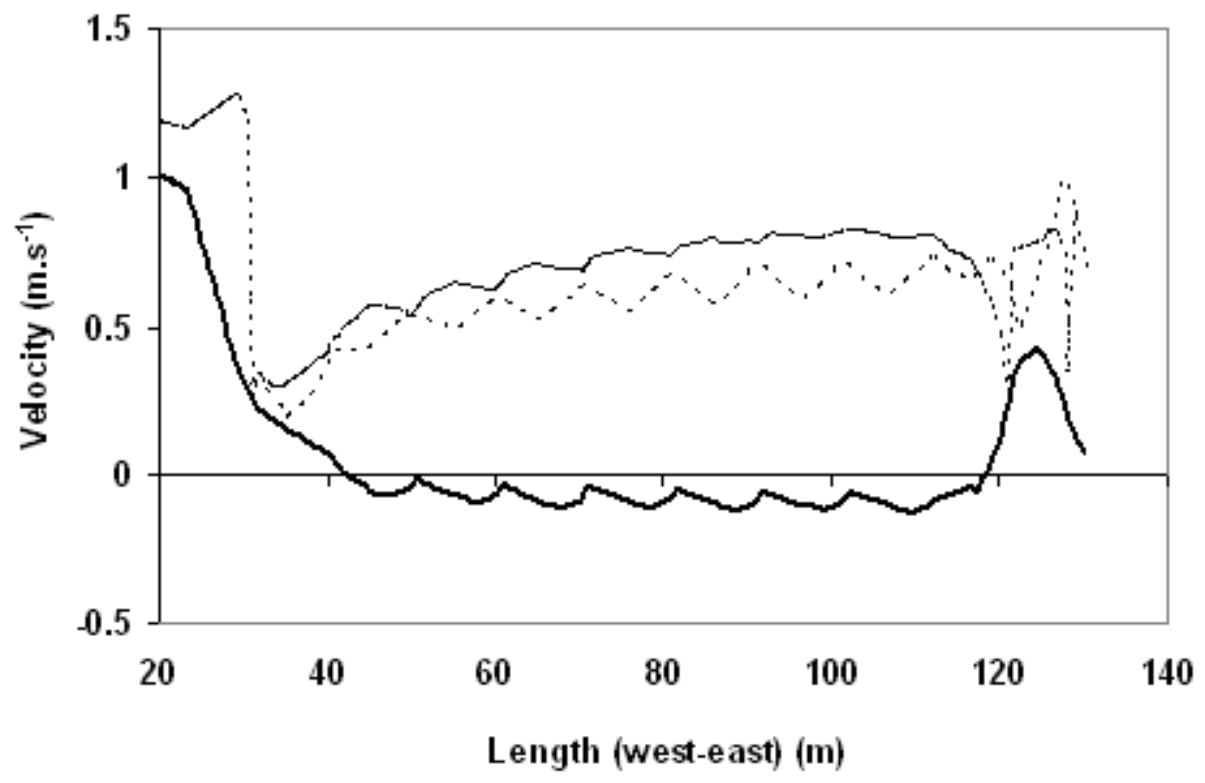

Fig. 7. Modelled horizontal air velocity profiles across the middle of the greenhouse along $W$ E direction at 3 different heights: $1 \mathrm{~m}$ (—);3 $\mathrm{m}(-\ldots \ldots) ; 4 \mathrm{~m}$ (— 


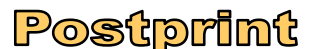

Version définitive du manuscrit publié dans / Final version of the manuscript published in : Agricultural and Forest Meteorology, 2009, vol.149, no.6-7, DOI : 10.1016/j.agrformet.2009.01.002:

1

2

3

4

5 


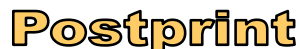

Version définitive du manuscrit publié dans / Final version of the manuscript published in : Agricultural and Forest Meteorology, 2009, vol.149, no.6-7, DOI : 10.1016/j.agrformet.2009.01.002:

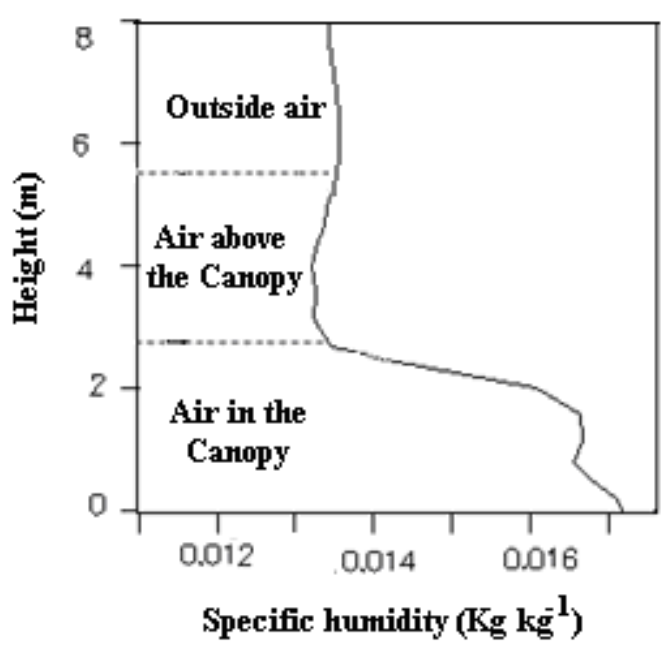

Fig.9. Modelled vertical profile of air humidity in the centre of the greenhouse between two successive roof openings. 


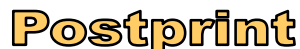

Version définitive du manuscrit publié dans / Final version of the manuscript published in : Agricultural and Forest Meteorology, 2009, vol.149, no.6-7, DOI : 10.1016/j.agrformet.2009.01.002

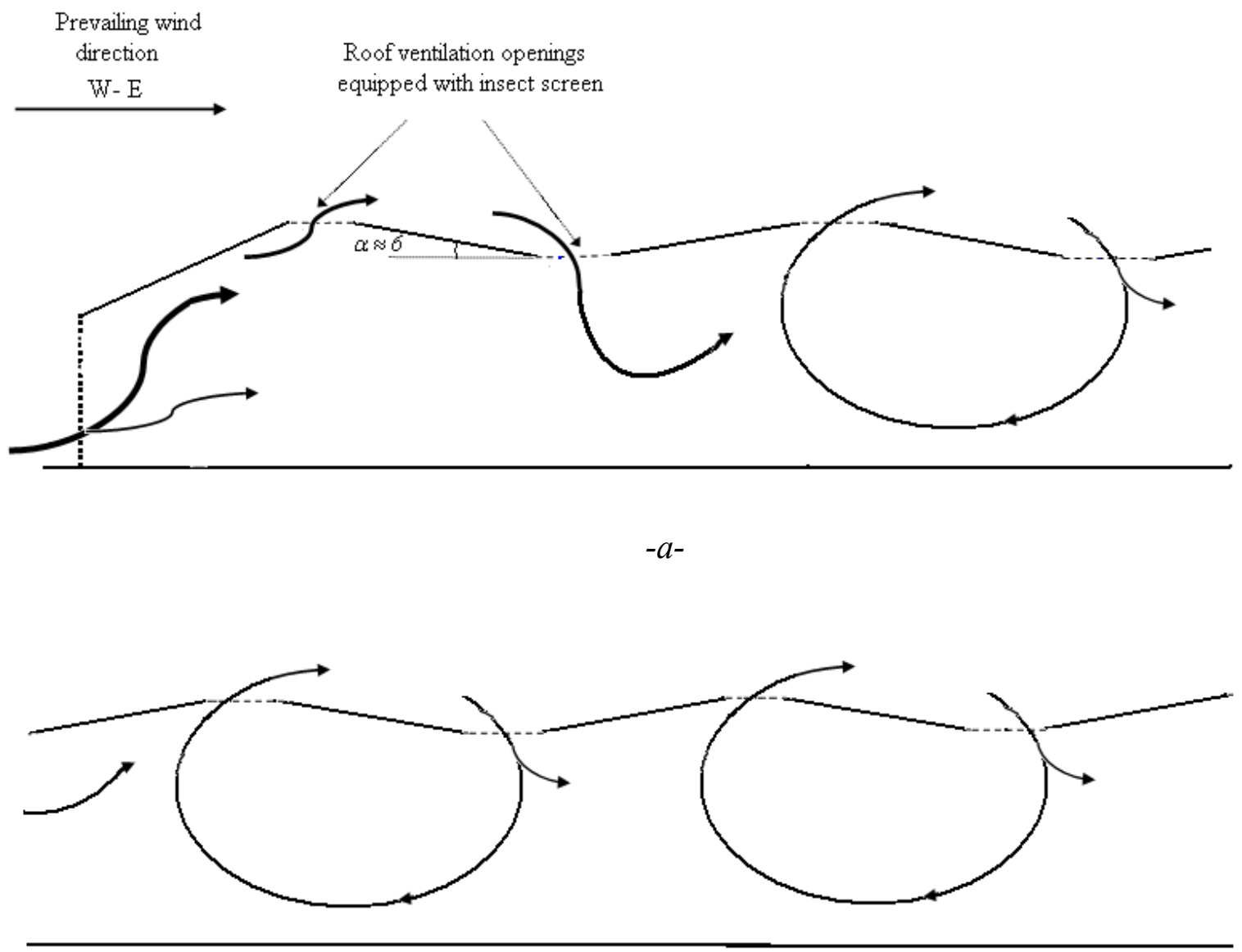

$-b-$

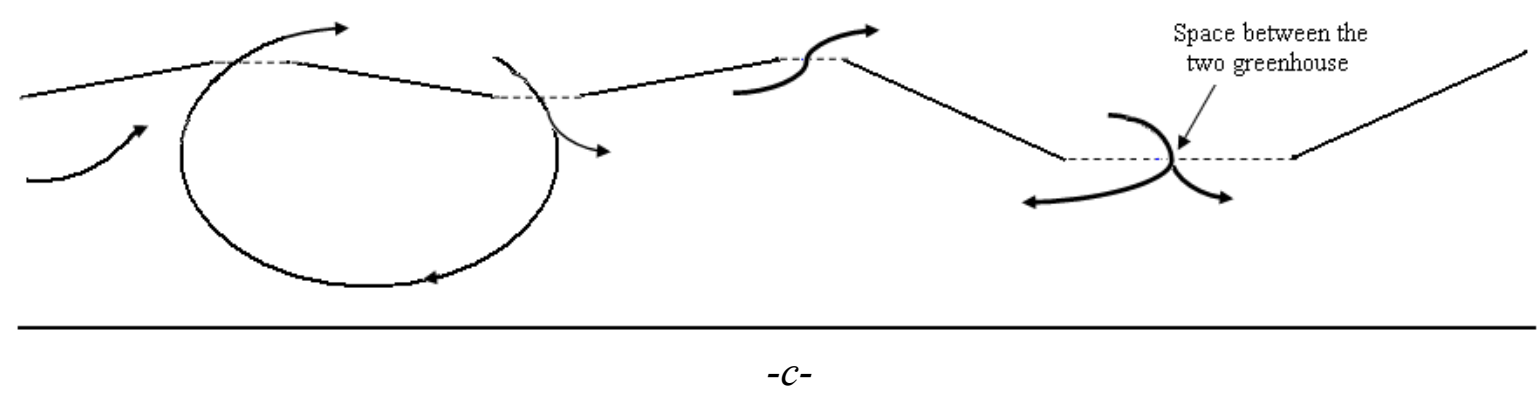

Fig.10. Reconstitution of air circulation within the greenhouse from $W$ to $E$, halfway along $N$ S direction.

a: at the windward end of the greenhouse

$b$ : in the middle of the greenhouse

$c$ : at the leeward end of the greenhouse 


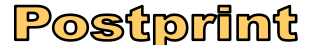

Version définitive du manuscrit publié dans / Final version of the manuscript published in : Agricultural and Forest Meteorology, 2009, vol.149, no.6-7, DOI : 10.1016/j.agrformet.2009.01.002:

1

2

3

4

5

6

7

8

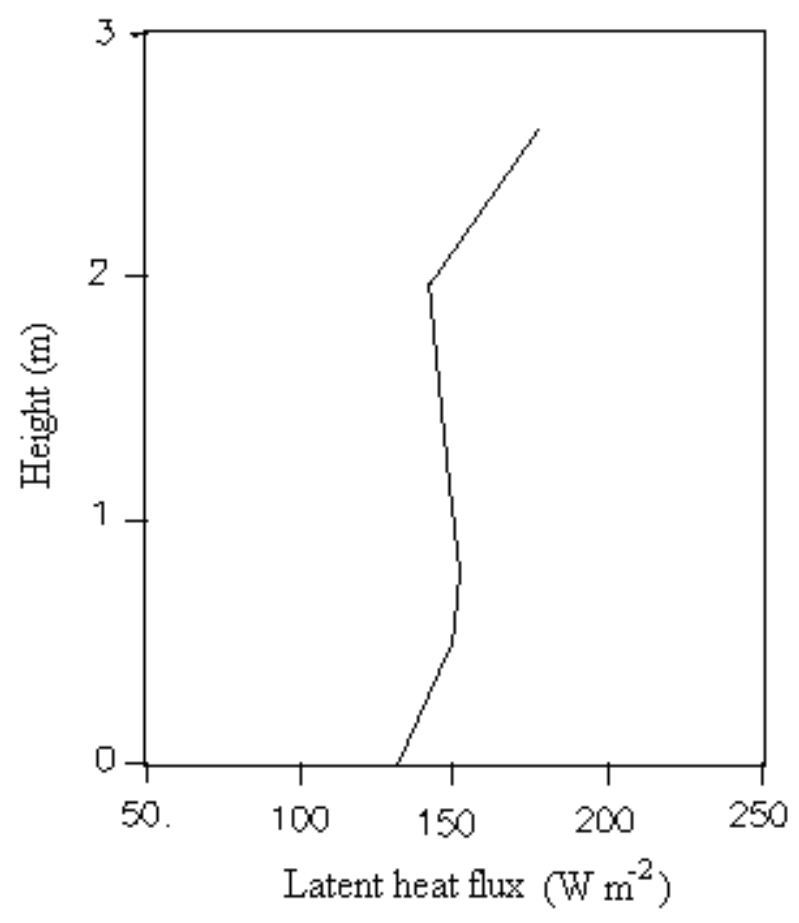

Fig. 11. Modelled vertical distribution of the latent heat of the canopy transpiration flux in the centre of the greenhouse 


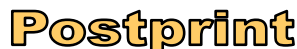

Version définitive du manuscrit publié dans / Final version of the manuscript published in : Agricultural and Forest Meteorology, 2009, vol.149, no.6-7, DOI : 10.1016/j.agrformet.2009.01.002:

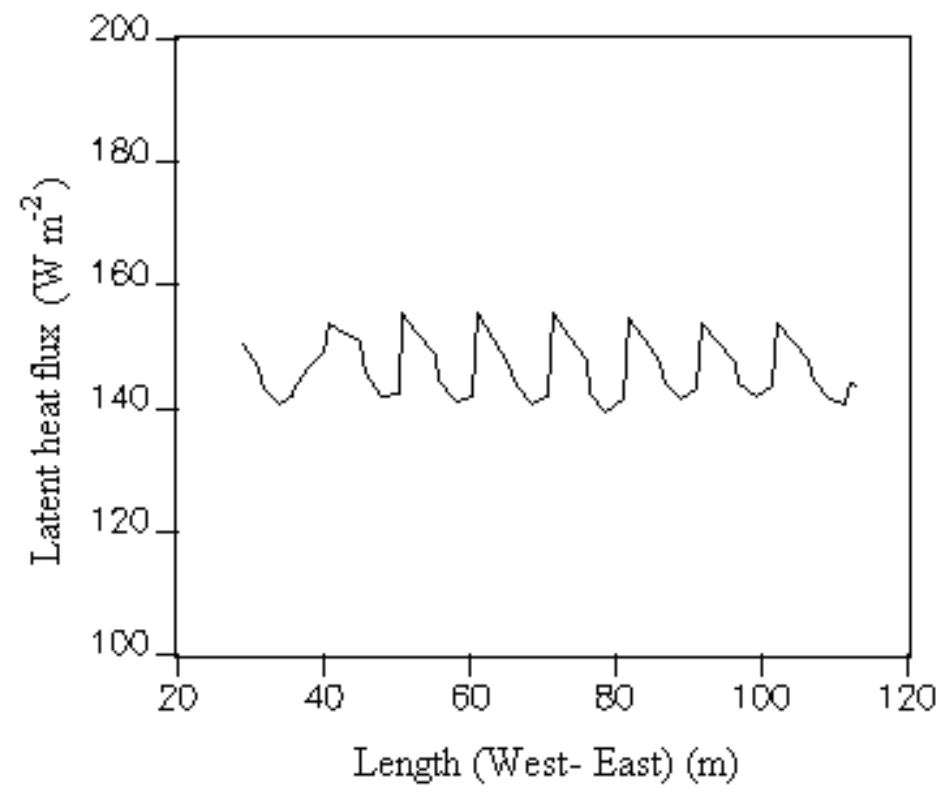

Fig.12. Modelled longitudinal transpiration flux distribution from West to East at $1 \mathrm{~m}$ above ground in the middle of the greenhouse 


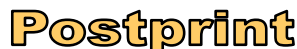

Version définitive du manuscrit publié dans / Final version of the manuscript published in : Agricultural and Forest Meteorology, 2009, vol.149, no.6-7, DOI : 10.1016/j.agrformet.2009.01.002:

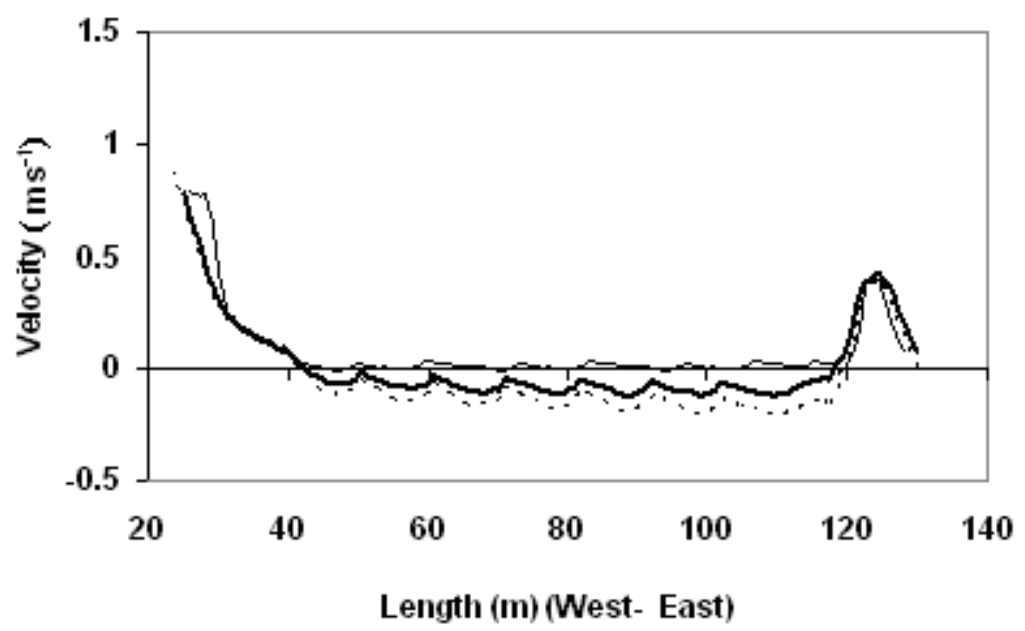

Fig. 13: Modelled horizontal windwise greenhouse air velocity distributions from West to East at $1 m$ height for the three cases of plant distribution considered

i) Canopy considered as a single block (

ii) Canopy rows perpendicular to prevailing wind direction ( iii) Canopy rows parallel to the prevailing wind direction (

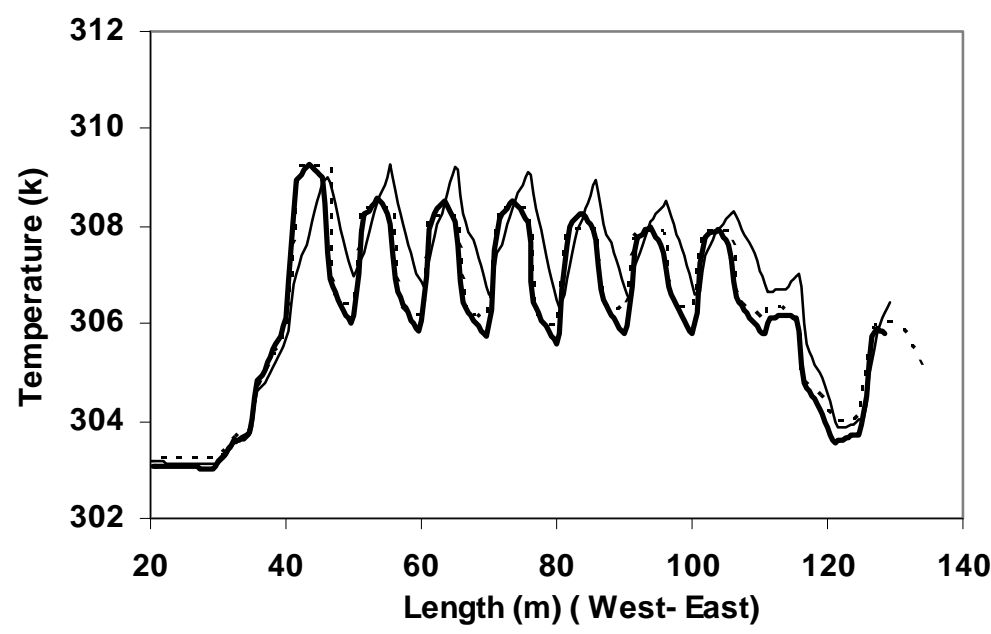

16

Fig. 14: Modelled horizontal temperature distributions from West to East at $1 m$ height for the three cases of plant distribution considered

i) Canopy considered as a single block (__)

ii) Canopy rows perpendicular to the prevailing wind direction (___

iii) Canopy rows parallel to the prevailing wind direction (. 


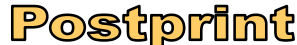

Version définitive du manuscrit publié dans / Final version of the manuscript published in : Agricultural and Forest Meteorology, 2009, vol.149, no.6-7, DOI : 10.1016/j.agrformet.2009.01.002:

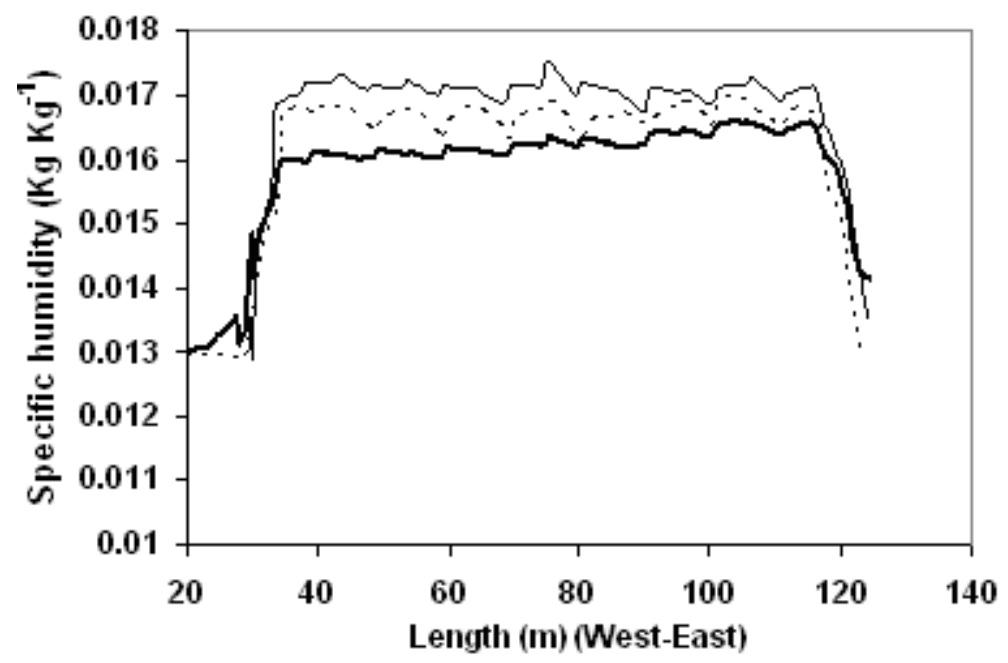

Fig. 15: Modelled horizontal air humidity distributions from West to East at $1 m$ height for the three cases of plant distribution considered i) Canopy considered as a single block (

ii) Canopy rows perpendicular to the prevailing wind direction ( iii) Canopy rows parallel to the prevailing wind direction (- 


\section{P๑s\}}

Version définitive du manuscrit publié dans / Final version of the manuscript published in : Agricultural and Forest Meteorology, 2009, vol.149, no.6-7, DOI : 10.1016/j.agrformet.2009.01.002:

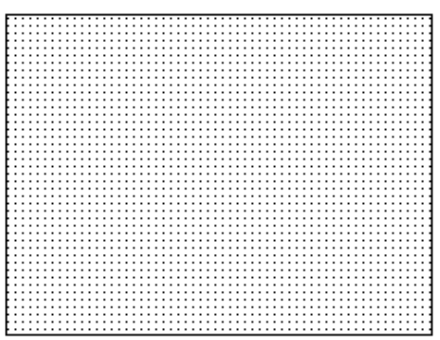

Whole canopy leaf sutface distributed into a single parallelepiped block

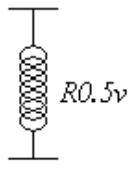

(1)

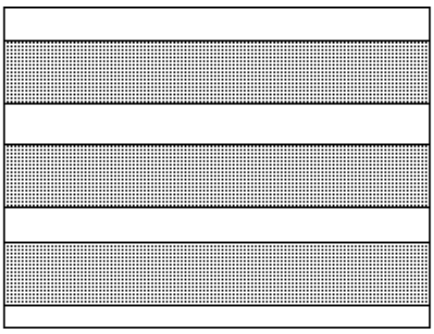

Whole canopy leaf surface distributed into rows perpendicular to the direction of the flow

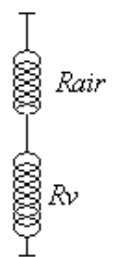

(ii)

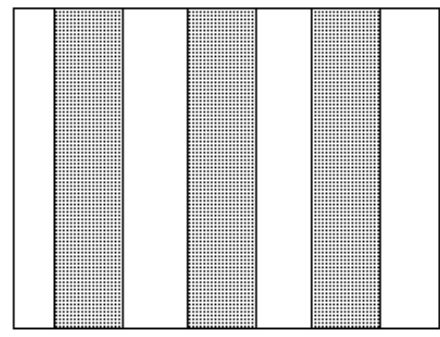

Whole canopy leaf surface distributed into rows parallel to the direction of the flow

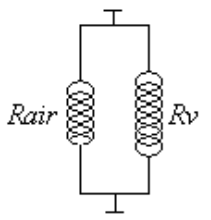

(11)
7 